\title{
A FAUNA COMO INSTRUMENTO DE ANÁLISE DA COMPLEXIDADE GEOGRÁFICA DOS AMBIENTES NATURAIS. O CASO DE Carponis melanocephala NO PARQUE ESTADUAL INTERVALES E ENTORNO - SP
}

\author{
Eduardo Silva Bueno ${ }^{1}$ \\ Sueli Angelo Furlan ${ }^{2}$
}

Resumo: O objetivo desta pesquisa é desenvolver a seguinte questão: o estudo da fauna pode contribuir para a análise da complexidade geográfica dos ambientes naturais, bem como no esclarecimento da forma de apropriação destes pelo homem? Concluiu-se que o papel da fauna é importante. Isso porque pode ser estudada sob determinado ponto de vista geográfico, da complexa inter-relação entre distintas unidades espaciais dadas em diferentes escalas. Desse modo, pode contribuir muito para a identificação de lacunas nos procedimentos históricos relativos à proteção de ambientes naturais. Especificamente, se mostrou útil na proposição do estabelecimento de determinados tipos de unidades de conservação e ao tipo de ambientes que estas visam proteger. Este estudo concretiza tal tipo de abordagem no setor paulista da Serra de Paranapiacaba, mais precisamente no Parque Estadual Intervales e entorno - SP.

Palavras-chave: Fauna; Geografia; Cartografia Ambiental; Unidades de Conservação.

\section{FAUNA AS AN INSTRUMENT OF ANALYSIS OF GEOGRAPHIC COMPLEXITY OF NATURAL ENVIRONMENTS. THE CASE OF Carponis melanocephala IN THE INTERVALES STATE PARK AND SURROUNDINGS - SP}

\begin{abstract}
The purpose of this research is to develop the following question: can fauna studies contribute to the analysis of the geographic complexity of natural environments, as well as to the understanding of human apropriation of these environments? It was concluded that fauna play an important role in these issues, because it can be studied from a geographic point of view, in other words, from the complex relation among distinct spatial units given at different scales. In this way, it can make significant contributions to the identification of lacks in the historical procedures related to the protection of natural environments. Specifically, fauna studies have shown to be useful in the proposition and creation of particular kinds of conservation units and to the kind of environments that they aim to protect. This study materializes such approach in the paulista part of Paranapiacaba mountain range, especially in the Intervales State Park and surroundings - SP.
\end{abstract}

Keywords: Fauna; Geography; Environmental Cartography; Conservation Units.

\footnotetext{
${ }^{1}$ Bacharel em Geografia, Mestrando em Geografia Física na Universidade de São Paulo (USP) - E-mail: eduardosilvabueno@yahoo.com.br 2 Bacharel e Licenciada em Biologia e Geografia, Mestre em Geografia Física, Doutora em Geografia Física, Professora Assistente na Universidade de São Paulo (USP) - E-mail: sucaangf@usp.br DOI: 10.7154/RDG.2012.0023.0007
} 


\section{INTRODUÇÃO}

A paisagem é constituída por dois componentes: o suporte ou forma (orogênese, estratigrafia e litologia) e a cobertura ou tecido ecológico (parâmetros climáticos, biogeográficos e antrópicos) (DELPOUX, 1974). Bertrand (1971, p. 2) a conceitua como "[...] o resultado da combinação dinâmica, portanto instável, de elementos físicos, biológicos e antrópicos [...]".

Percebe-se que a paisagem é composta pelos elementos bióticos, dentre os quais a fauna também faz parte, entretanto, os poucos estudos geográficos realizados sob uma perspectiva sistêmica tendem a limitar a utilização da fauna como bioindicador de unidades da paisagem. Este estudo propõe abordá-la sob o ponto de vista geográfico, conforme Silva (1986), como elemento que trata do objeto da geografia, ou seja, da relação entre as categorias geográficas.

Desse modo, se partirá de sua visão como bioindicador para elaborarmos uma base que possibilite uma análise geográfica do ambiente a que está associada.

Não somente a presença física da biosfera afeta ou influencia a aparência da paisagem, mas também através de sua atividade a fisionomia da terra é fortemente modificada (UDVARDY, 1969).

Lança-se a pergunta: não poderia a biosfera através de sua atividade, mais do que modificar a fisionomia terrestre, evidenciar regiões de geodiversidade desconhecida e por isso mal apropriada e pouco preservada pela sociedade a que está vinculada, quando se pensa em questões ambientais e conservacionistas? Mais especificamente, como se poderia abordar a fauna nesta questão?

Análises mais associadas a um ponto de vista sistêmico ou que se encaixam melhor em estudos relacionados à geografia física se expressam bem na idéia de Moss exposta por Gregory (1992), baseada no modo pelo qual o meio a mbiente funciona e naquilo que ele faz em vez de analisar o que ele é.

Entende-se que a visão sistêmica pode fornecer dados e fundamentos consistentes para um estudo que proponha fazer uma análise não sistêmica, que enfoque a relação sociedadenatureza sob o ponto de vista da relação entre o singular, o particular e o global de forma geográfica, ou seja, a complexidade da inter-relação entre distintas unidades espaciais dadas 
em determinadas categorias geográficas em diversas escalas (unidades de paisagem, paisagem e região).

No estudo que se realizou, não é de interesse conhecer e explicar a distribuição da população de uma espécie em si através de relações verticais ou ecológicas. O interesse está em utilizá-la para o melhor conhecimento da distribuição das unidades de paisagens singulares agrupadas, através da identificação de padrões espaciais que demonstram a particularidade desses agrupamentos ao relacionar suas características locais com o padrão espacial global a que estão associados. Acredita-se assim poder realizar um estudo que relacione zoogeografia e geografia, que contribua para uma análise conservacionista do ponto de vista espacial.

Procedimentos sistêmicos elaborados para a espacialização do nicho ecológico da fauna específica de determinado ambiente natural, poderão fornecer base para a análise da relação que a sociedade tem com a natureza, com os ambientes naturais que visa proteger, apontando a percepção histórica destes sob determinado aspecto geográfico, e equívocos daquela quanto à proteção dos mesmos.

Desse modo, pode-se utilizar a visão sistêmica como procedimento operacional de pesquisa em geografia física, sempre na tentativa de descobrir o que o meio ambiente é, procurando desvendar sua complexidade e apontar formas de melhor protegê-lo através de medidas conservacionistas. Neste artigo apresentam-se os fundamentos que sustentam este raciocínio aplicado em determinada realidade.

\section{Área e espécie estudados}

O estudo foi realizado no Parque Estadual Intervales (PEI) e seu entorno delineado pela sua Zona de Amortecimento ${ }^{3}$ (Figura 1). Tal parque localiza-se no sul do Estado de São Paulo, em parte da Serra de Paranapiacaba, denominação local para a Serra do Mar, se encontra entre $24^{\circ} 12^{\prime}$ a $24^{\circ} 25^{\prime}$ de latitude $S$ e $48^{\circ} 03^{\prime}$ a $48^{\circ} 30^{\prime}$ de longitude $O$ e tem área de 49888 ha (FUNDAÇÃO FLORESTAL, 1998).

O PEl situa-se no divisor de águas entre os vales dos rios Paranapanema e do Ribeira, abriga uma extensa rede de drenagem protegida pela Mata Atlântica que cobre toda sua extensão,

\footnotetext{
${ }^{3}$ A Zona de Amortecimento foi elaborada no Plano de Manejo do PEI de 2008. Esta referencia é citada na bibliografia como SÃO PAULO (2008).
} 
sua altitude varia entre 60 e 1095 metros, ocorrendo assim em relevos de planícies e de vertentes (FUNDAÇÃO FLORESTAL, 1998). Em sua maior parte, constitui-se sobre as terras do Cinturão Orogênico do Atlântico que no passado sofreram diversos dobramentos responsáveis pela gênese das rochas cristalinas existentes na área (predominantemente granítico-gnaissicas). Estas, por serem mais resistentes ao intemperismo característico de sistemas tropicais úmidos, sustentam terrenos mais altos que os adjacentes em forma de serras escarpadas e morros que abrangem amplo gradiente altitudinal. A modelagem da superfície é composta de estreitos e profundos vales cobertos por vegetação de Floresta Tropical Fluvial em diversos estágios sucessionais.

A espécie escolhida para ter seu nicho ecológico espacializado no PEl e entorno é Carponis melanocephala, cujo nome popular é sabiá pimenta ou cochó (Figura 2A). O gênero Carponis representa espécies de cotingas de porte médio, está confinado nas florestas do sudeste brasileiro que cobrem as montanhas da Serra do Mar na estreita faixa costeira entre o mar e o oceano (SNOW, 1982). A distribuição de Carponis melanocephala na costa braseira se estende de Alagoas a Santa Catarina (Figura 2B).

Tal espécie ocorre predominantemente na floresta atlântica de encosta e na baixada litorânea entre 0 e 400 metros de altitude (SIGRIST, 2005) se estendendo até os 500 metros de altitude e localmente até os 700 metros, mas na maioria das vezes é encontrada abaixo dos 300 metros (HOYO; ELLIOTT; CHRISTIE, 2004). Isso porque é uma espécie típica das terras baixas das serras atlanticas, ocorrendo preferencialmente em florestas maduras submontanas e de planície costeira. Pretende-se compreender até onde ambientes relacionados a essas terras podem se distribuir na área de estudo, que se caracteriza por ter grande quantidade de área em terras de altitudes intermediárias a altas dominadas por florestas montanas e altomontanas. Isso porque se sabe que a espécie possui amplitude altitudinal de 995 metros (CORDEIRO, 2001) e que populações da mesma já foram registradas no Parque Estadual Jurupará - PEJ (Ibiúna, SP) por Develey (2004). Tal parque situa-se em outra área componente do Contínuo Ecológico de Paranapiacaba, foram registrados 36 contatos de Carponis melanocephala, em local cuja altitude varia entre 700 e 850 metros.

Conforme Pizo et al. (2002) as cotingas se alimentam também de frutos da mata secundária, de matas com algum distúrbio e do palmiteiro. Procuram fragmentos onde haja mata suficiente para fornecer alimento, se movimentando entre habitats da floresta Atlântica, 
implicando assim em movimentos altitudinais (PIZO et al., 2002). Carponis melanocephala consome frutos de árvores da borda da floresta das terras baixas do PEI (PIZO et al., 2002), existido a possibilidade assim de ser observada em matas secundárias tardias.

Existe a possibilidade de Carponis melanocephala sobreviver em área de floresta secundária, pois, segundo Aleixo (1997) pertence a uma guilda da avifauna que possui alta biomassa e grande capacidade de deslocamento. Desse modo, pode se adaptar a condições locais de suprimentos e frutos.

As terras baixas do PEI, mais precisamente da Base de Pesquisa Saibadela (Figuras 1 e 2C), situada no extremo leste daquele, em $24^{\circ} 14^{\prime} \mathrm{S}$ e $48^{\circ} 05^{\prime} \mathrm{W}$; altitude de 80 metros segundo Guix et al. (2002), possuem populações de Carponis melanocephala (ALEIXO; GALETTI, 1997; ALEIXO, 1997). É baseado nos registros de campo obtidos nesta base associados às exigências ambientais da espécie, que espacializou-se seu nicho ecológico, ou seja, paisagens que vão das mais às menos semelhantes à de Saibadela, local ótimo para sua reprodução.

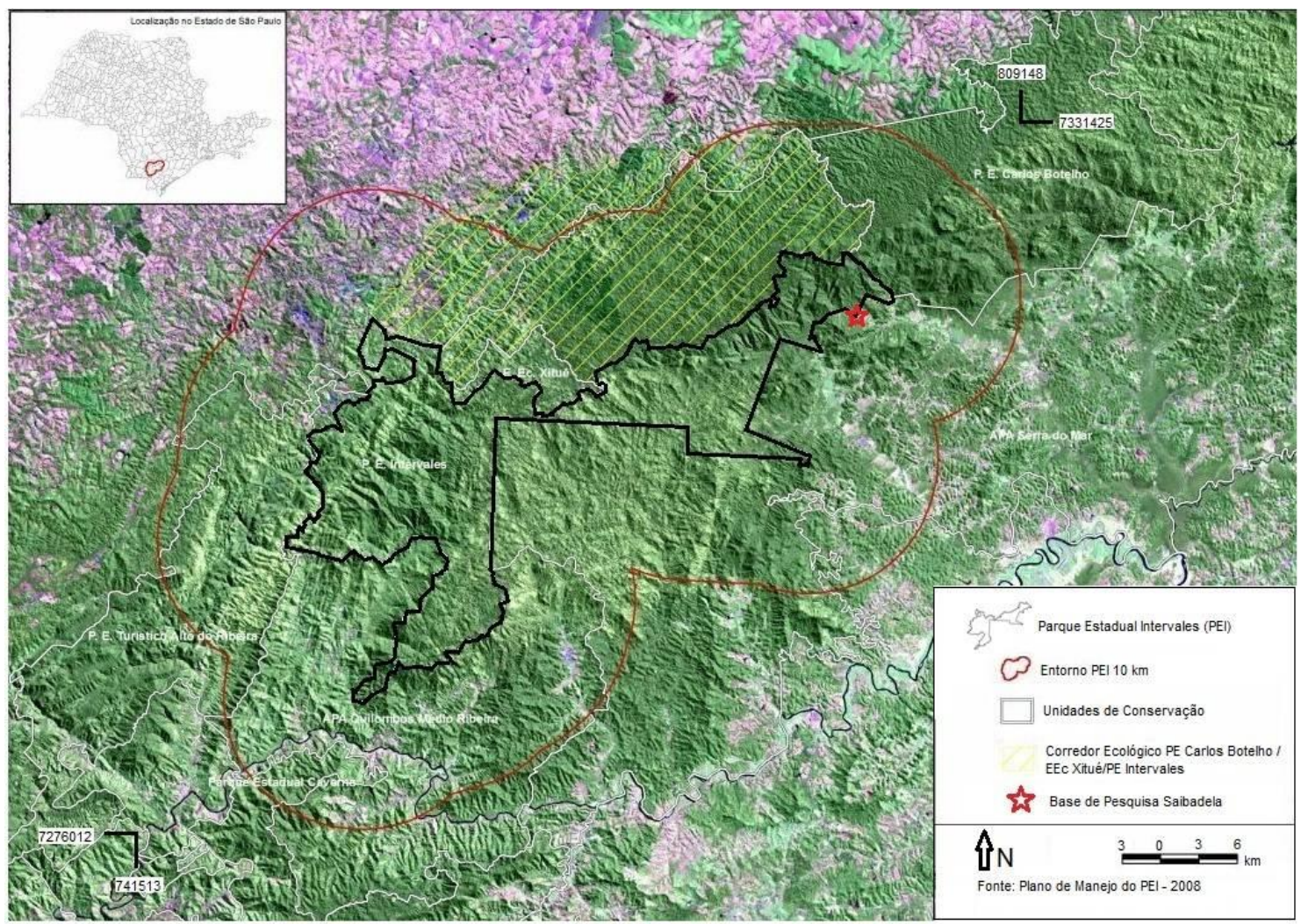

Figura 1: Área de estudo. Adaptação: Eduardo Silva Bueno, Helga Grigorowitschs - 2009. 

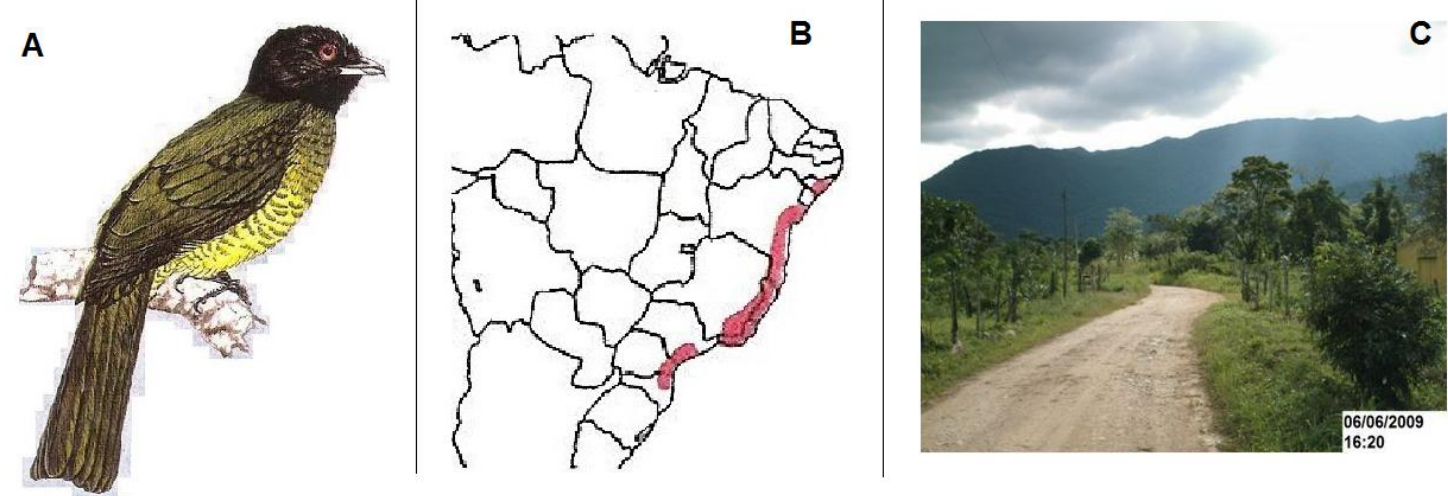

Figura 2: A - Carponis melanocephala / B - sua distribuição na costa brasileira. Fonte: SIGRIST (2005) / C- Serra de Paranapiacaba vista da Base de Pesquisa Saibadela. Autor: Eduardo Silva Bueno - 2009.

\section{MÉTODO}

Conceitualmente entendemos que a paisagem é

[...] um mosaico heterogêneo formado por unidades interativas, sendo esta heterogeneidade existente para pelo menos um fator, segundo um observador e numa determinada escala de observação. Esse mosaico heterogêneo é essencialmente visto pelos olhos do homem, na abordagem geográfica, e pelo olhar das espécies ou das comunidades estudadas na abordagem ecológica [...] (METZGER, 2001, p. 1).

Tentou-se combinar os dois olhares, essa será a referência metodológica que orientará a abordagem dos conceitos utilizados no método elaborado.

No ponto de vista da espécie (abordagem "ecológica"), "[...] o mosaico é considerado como um conjunto de habitats que apresentam condições mais ou menos favoráveis para a espécie ou a comunidade estudada [...]" (METZGER, 2001, p. 4).

Entende-se esse conjunto de habitas como conjunto de unidades de paisagem, isso porque se utilizou as exigências do nicho ecológico da espécie quanto à sobreposição de determinadas variáveis ambientais, para identificarmos áreas semelhantes e distintas daquela onde foi registrada em campo. Desse modo, a espécie foi utilizada para definir, conforme Delpoux (1974), unidades de paisagem homogêneas em suporte e cobertura.

A área de registro em campo foi tomada como parâmetro de área ideal para ocorrência da espécie porque a literatura diz que área de reprodução é aquela que representa seu ótimo ecológico, a área que melhor satisfaz suas exigências ambientais (STEVENS, 1989; DAJOZ, 2006). 
Baseados em Brown e Lomolino (2006) entende-se que o nicho das espécies representa as combinações de variáveis ambientais, que permitem a sobrevivência dos indivíduos e a manutenção das populações.

Para se representar o nicho ecológico da espécie escolhida utilizou-se a idéia de potencial biótico, termo que consiste na capacidade que as espécies têm de viver em dado ambiente (MARTINS, 1992). Desse modo, o habitat pode ser associado a determinada unidade de paisagem com determinado potencial biótico sob o ponto de vista de Carponis melanocephala.

Seguindo o exposto por Metzger (2001), o ponto de vista do homem será abordado na medida em que se utilizou a concepção de que as paisagens identificadas são unidades de cobertura ou de uso e ocupação da terra distintos, conforme a abordagem geográfica.

Segundo Turner (1989), a região é formada por um conjunto de paisagens, que por sua vez, são unidades espacialmente heterogêneas. Desse modo, acredita-se que são formadas por unidades de paisagem.

Conforme La Blache (1888-1889), entende-se que a região é concreta. Isso porque, como diz Clozier, a paisagem foi elaborada individual e historicamente, sendo indicativa da realidade (CHRISTOFOLETTI, 1976).

A espacialização do nicho ecológico de determinada espécie pode evidenciar a ocorrência na realidade de regiões naturais ainda não percebidas pelo homem sob o ponto de vista da importância de sua conservação, e desse modo, pouco protegidas das ações antrópicas relativas ao avanço de áreas urbanas e rurais sobre áreas florestadas em determinados locais ao longo do tempo.

Entende-se que a região é a categoria que melhor relaciona elementos singulares dados por categorias abstratas e idealizadas para melhor entender a realidade estudada em escala de detalhe como a paisagem, com elementos universais reconhecidos em qualquer ambiente do globo. Desse modo, é a categoria que representa a unidade geográfica, a relação sociedade-natureza dada de forma concreta no espaço pela totalidade, ou seja, conforme Corrêa (2005), pela intersecção de eventos globais e locais, universais e singulares respectivamente, que a nosso ver particulariza determinada forma de apropriação do meio pela sociedade.

Autores como Coutinho (1960) e Tarifa (2002) sugerem que tanto do ponto vista biológico como geográfico, os ambientes dos setores alto, médio e baixo da encosta do Planalto 
Atlântico cobertos por florestas pluviais tropicais, possuem certa homogeneidade ambiental entre si, sendo a diferença entre os mesmos dada por questões topo e microclimáticas.

As matas médias de encosta abrigam microclimas um pouco mais permeáveis e obstrução do céu um pouco menor que a mata alta de baixa encosta, mas topoclimaticamente são protetoras do ambiente abaixo do dossel e mantêm ritmos úmidos muito freqüentes como as matas altas de encosta (TARIFA, 2002). Interpretando o escrito por esse autor, entende-se que um dos fatores que gera as pequenas diferenças entre tais matas é que as baixas vertentes da média encosta possuem área de relevo convexo ou embaciamentos onde se situam vales achatados, menos amplos que as de baixa encosta onde o relevo é mais plano e menos declivoso ainda. Nesta perspectiva de pensamento se poderia pensar que mesmo na baixa vertente da alta encosta, podem existir tais vales achatados e embaciamentos em menor amplitude, já que neste trecho ocorre um contato mais abrupto entre o padrão de declividade das vertentes e do fundo de vale. Tais embaciamentos teriam amplitude bem menor porque aí, devido à alta declividade da encosta, as vertentes de ambas as margens dos rios tendem a ficarem mais próximas no fundo de vale, não havendo ampla planície que as separe. Sendo assim, potencialmente, a floresta submontana tem condições de se reproduzir, no mínimo, na média vertente da floresta das altitudes intermediárias (influenciadas pelo sopé) e na baixa vertente das de altitudes superiores.

A encosta também parece ter certa homogeneidade quanto à percepção da espécie em estudo. Isso porque se realizou uma vasta pesquisa em diversas teses, artigos e base de dados sobre levantamentos florísticos realizados em Floresta Ombrófila Densa da Mata Atlântica e situados em áreas de transição desta com outros tipos florestais. Nosso intuito foi de conhecer melhor a distribuição espacial das espécies vegetais que Carponis melanocephala se alimenta em Saibadela, conforme o estudo realizado por Pizo et al. (2002), que publicou uma lista das plantas consumidas por cotingídeos habitantes das terras baixas do Sudeste brasileiro.

Foi pesquisado o maior número de trabalhos possíveis, desde o Espírito Santo até Santa Catarina (somente um trabalho consultado foi realizado na Bahia), que representam bem os limites do trecho sul da vegetação de Mata Atlântica brasileira por qual Carponis melanocephala se distribui (SNOW, 1982).

As teses que nos orientaram na busca por bibliografias foram as de Custódio Filho (2002), Oliveira (2006) e Sanchez-Lacerda (2001), pois são bem representativas de estudos 
realizados em diversos tipos de formações vegetais da Mata Atlântica e do gradiente altitudinal da Floresta Ombrófila Densa de encosta. Ao todo consultamos oitenta e cinco levantamentos.

No Quadro 1 observa-se que as espécies as quais tal cotingídeo se alimenta em Saibadela, em linhas gerais, se distribuem pelas formações montanas [conforme Veloso e Góes Filho (1982), se estendem até 1500 metros na área do PEI] e secundárias tardias, do mesmo modo que nas formações de terras baixas e submontanas.

Floristicamente, Carponis melanocephala parece ter menor capacidade de habitar as formações altomontanas, ripáras, de várzeas e abertas (estas últimas são normalmente secundárias iniciais, intermediárias ou de bambus, conforme Mantovani e Pavão, 2008). Já as fitofisionomias que constituem a área de contato das Florestas Ombrófila Densa com a Mista e esta última, representam habitas possivelmente impróprios, de potencial mínimo para a sobrevivência de Carponis melanocephala.

Quanto às topossequências da vertente, em linhas gerais, o que se percebe é que as espécies vegetais do Quadro 1, têm a tendência de se distribuirem de forma mais homogênea nos diversos trechos da vertente, sendo o topo de morro a área com potencial menor.

Simonetti (2001) ao estudar a relação entre a vegetação e diferentes compartimentos morfodinâmicos das encostas existentes na bacia do rio Itamambuca em Ubatuba - SP, para realizar uma análise detalhada, baseada em procedimentos empírico/ecológicos, selecionou uma sub-bacia de um afluente que representaria os processos decorrentes nas encostas da bacia inteira. Para isso, selecionou uma sub-bacia que se assemelhasse ao gradiente altitudinal da encosta drenada pelo rio Itamambuca. A sub-bacia selecionada compreende uma área que se estende de um trecho mais baixo do platô até a planície do citado rio.

Simonetti (2001) trabalhou com a setorização da vertente em parte de planície aluvial, coluvial (baixa vertente, limite entre vale e encosta), média e alta vertente. Se a autora considerou que os processos existentes nas vertentes de uma sub-bacia relacionados à vegetação e relevo (variáveis fortemente atuantes na constituição de uma paisagem a nível local), podem representar aqueles decorrentes nas vertentes componentes de uma bacia inteira que corta a encosta de um trecho da Serra do Mar em Ubatuba, constituída por florestas relacionadas a gradiente altitudinal (florestas de terras baixas, submontanas e montanas), pode-se pensar que a distribuição das diferentes paisagens em nível local 
relacionadas a setores das vertentes, é semelhante em quaisquer vertentes que acompanham o desenho dos vales dos rios (principais ou afluentes), que descem do platô em direção à planície através da encosta da Serra do Mar.

Desse modo deduz-se que a semelhança entre florestas de média e baixa encosta pode ter relação com a semelhança entre setores da vertente (baixo, médio e alto), ou seja, paisagens que ocorrem nas vertentes da baixa encosta também se distribuem nas vertentes da média e alta encosta.

Esta interconexão pode ser diferente em distintos trechos da Serra de Paranapiacaba, devido aos aspectos universais da mesma, assim como em qualquer outra serra, se darem em gradientes topográficos distintos, com amplitude altitudinal alta, intermediária e baixa. Esta interconexão se revela um fenômeno regional porque associa a singularidade das unidades da paisagem vista sob o olhar de Carponis melanocephala com gradientes topográficos, fazendo perceber a real e particular distribuição das paisagens ao longo de toda extensão altitudinal em determinados setores do ambiente serrano.

Identificadas essas interconexões regionais, entende-se que se pode ilustrá-las através da elaboração de perfil tridimensional associado ao vale de determinados rios que desçam a encosta desde as terras altas até as baixas. Neste perfil pode-se representar a distribuição das paisagens obtidas ao longo de toda a amplitude altitudinal da encosta. Tal perfil representa a síntese do método de observação do ambiente natural do PEI e entorno visto sob os olhos de Carponis melanocephala. 


\begin{tabular}{|c|c|c|c|c|c|c|c|c|c|c|c|c|c|c|c|}
\hline & \multicolumn{10}{|c|}{ Formações vegetais } & \multicolumn{5}{|c|}{ Topossequências (setores) da vertente } \\
\hline & 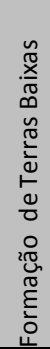 & 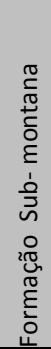 & 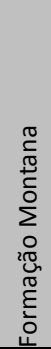 & 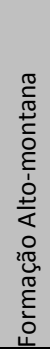 & 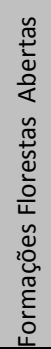 & 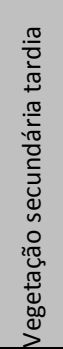 & 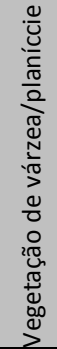 & 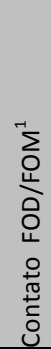 & 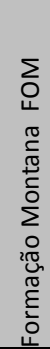 & 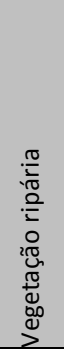 & 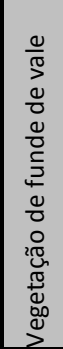 & 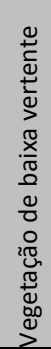 & 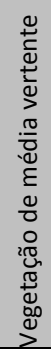 & 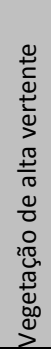 & 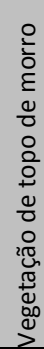 \\
\hline Arecaceae Euterpe edulis & $x$ & $x$ & $x$ & $x$ & $x$ & $x$ & $x$ & & & $x$ & $x$ & $x$ & $x$ & $x$ & $x$ \\
\hline Bixaceae Bixa orelleana $^{2}$ & & & & & & $x$ & & & & & & & & & \\
\hline Celastraceae Maytenus spp. & $\mathrm{x}$ & $\mathrm{x}$ & $x$ & $x$ & $\mathrm{x}$ & $\mathrm{x}$ & $\mathrm{x}$ & $\mathrm{x}$ & $x$ & $\mathrm{x}$ & $x$ & $\mathrm{x}$ & $\mathrm{x}$ & $\mathrm{x}$ & $x$ \\
\hline Chrysobalanaceae Hirtella hebeclada ${ }^{2}$ & $\mathrm{x}$ & $x$ & $x$ & $x$ & $x$ & $\mathrm{x}$ & $x$ & & & $x$ & $x$ & $x$ & $x$ & $x$ & $x$ \\
\hline Melastomataceae Henriettea succosa $a^{2}$ & $\mathrm{x}$ & $\mathrm{x}$ & & & $x$ & & & & & & & & & & \\
\hline Monimiaceae Mollinedia spp. & $x$ & $x$ & $x$ & $x$ & $\bar{x}$ & $\mathrm{x}$ & $x$ & $\mathrm{x}$ & $x$ & $x$ & $x$ & $x$ & $x$ & $x$ & $x$ \\
\hline Myristicaceae Virola $s p^{2}$ & $\mathrm{x}$ & $\mathrm{x}$ & $\mathrm{x}$ & $\mathrm{x}$ & $x$ & $x$ & $x$ & & & $x$ & $x$ & $\mathrm{x}$ & $\mathrm{x}$ & $\mathrm{x}$ & $x$ \\
\hline $\begin{array}{l}\text { Myrtaceae Campomanésia guaviroba }{ }^{2} \\
\text { Eugenia mosenii } \\
\text { Eugenia neoglomerata } \\
\text { Gomidésia anacardiifolia } \\
\text { Gomidésia spectabilis } \\
\text { Marlierea obscura } \\
\text { Marlierea suaveolens } \\
\text { Marlierea } \text { sp }^{3}\end{array}$ & $\begin{array}{l}x \\
x \\
x \\
x \\
x \\
x \\
x\end{array}$ & $\begin{array}{l}\mathrm{x} \\
\mathrm{x} \\
\mathrm{x} \\
\mathrm{x} \\
\mathrm{x} \\
\mathrm{x} \\
\mathrm{x}\end{array}$ & $\begin{array}{l}x \\
x \\
x \\
x \\
x \\
x \\
x\end{array}$ & $\begin{array}{l}x \\
x \\
x \\
x\end{array}$ & $\begin{array}{l}x \\
x\end{array}$ & $\begin{array}{l}\mathrm{X} \\
\mathrm{X} \\
\mathrm{X} \\
\mathrm{X} \\
\mathrm{X} \\
\mathrm{X} \\
\mathrm{X}\end{array}$ & $\begin{array}{l}x \\
x \\
x \\
x\end{array}$ & & & $\begin{array}{l}x \\
x \\
x \\
x \\
x\end{array}$ & $\begin{array}{l}x \\
x \\
x \\
x\end{array}$ & $\begin{array}{l}x \\
x \\
x \\
x \\
x\end{array}$ & $\begin{array}{l}x \\
x \\
x \\
x\end{array}$ & $\begin{array}{l}x \\
x\end{array}$ & $\mathrm{x}$ \\
\hline $\begin{array}{l}\text { Rubiaceae } \\
\text { Psychotria suterella } \\
\text { Psychotria } \text { sp }^{3}\end{array}$ & $\mathrm{x}$ & $\mathrm{x}$ & $\mathrm{x}$ & $\mathrm{x}$ & $\mathrm{x}$ & $\mathrm{x}$ & $\mathrm{x}$ & $\mathrm{x}$ & $\mathrm{x}$ & $\mathrm{x}$ & $x$ & $\mathrm{x}$ & $\mathrm{x}$ & $\mathrm{x}$ & $\mathrm{x}$ \\
\hline $\begin{array}{l}\text { Sapindaceae } \\
\text { Matayba elaeagnoides }\end{array}$ & $\mathrm{x}$ & $\mathrm{x}$ & $\mathrm{x}$ & $\mathrm{x}$ & $\mathrm{x}$ & $x$ & $x$ & $x$ & $x$ & & & & & $x$ & $x$ \\
\hline $\begin{array}{l}\text { Verbenaceae } \\
\text { Citharexylum myrianthum }\end{array}$ & $x$ & $x$ & $x$ & & $x$ & $x$ & $x$ & & & $x$ & & $x$ & $x$ & $x$ & \\
\hline Total de espécies & 16 & 16 & 15 & 11 & 12 & 16 & 12 & 4 & 4 & 12 & 10 & 12 & 12 & 11 & 8 \\
\hline
\end{tabular}

Quadro 1 - Distribuição das espécies vegetais consumidas por Carponis melanocephala ao longo das encostas e vertentes da costa leste brasileira

${ }^{1}$ FOD: Floresta Ombrófila Densa/ FOM: Floresta Ombrófila Mista. ${ }^{2}$ Essas espécies não se encontram na lista de PIZO et al. (2002). Bixa orelleana e Henriettea succosa foram retiradas de Collar et al., (1992). Hirtella hebeclada e Virola sp foram retiradas de SIGRIST (2005). Campomanésia guaviroba foi observada no primeiro trabalho de campo (01 a 06 de janeiro de 2009 ), como árvore fornecedora de alimento à Carponis melanocephala.

${ }^{3}$ Esses vegetais não foram identificados taxionomicamente em nível de espécies no estudo de PIZO et al., (op cit). Como existem no quadro espécies do mesmo gênero, não consideramos esses vegetais na análise, já que a prioridade foi a análise de diferentes espécies e não de gêneros. 
Técnica

Para se obter uma amostra da área de reprodução da espécie, primeiramente fizeramse dois trabalhos de campo na Base de Pesquisa Saibadela do PEI, com o intuito de obter o maior número de registros nas maiores distâncias possíveis percorridas através de trilhas.

Nosso intuito foi o de registrar vocalizações da espécie através do uso de playback (vocalizações induzidas através de reprodução do canto gravadas em CD). Tal recurso foi utilizado em locais de baixada (grotas) e de mata bem desenvolvida (árvores grandes, sub-bosque menos denso), aos olhos e percepção de experiente guia especialista em aves da Serra de Paranapiacaba acompanhante das atividades de campo.

Considerando o exposto por Aleixo (1997) entende-se que cada vocalização registrada de forma induzida (uso do playback) ou ao acaso (registro constatado ao se caminhar as trilhas), representa um contato a ser associado a coordenadas geográficas do ponto em que foi obtido. As coordenadas foram obtidas através de um GPS portátil.

A Área de Reprodução Amostral foi delimitada pelo método areográfico. Este se baseia na localização do indivíduo da espécie em campo que representa um ponto. Tal método se utiliza da nuvem de pontos, assim, considera um ponto como uma representação da unidade populacional e que obrigatoriamente terá que ser forçado a se tornar uma unidade espacial (ZUNINO; ZULINI, 2003). Desse modo, tal nuvem corresponderá à área que abrange os pontos que representam a localização exata de onde Carponis melanocephala teve sua vocalização registrada.

A unidade elementar é obtida através do traçamento de um raio em cada ponto que delimitará um círculo ao redor daquele. O valor desse raio é obtido a partir do desvio padrão calculado através dos valores dos segmentos (distâncias em linha reta) que unem os pontos de localização (ZUNINO; ZULINI, 2003). O limite externo do conjunto desses círculos corresponderá ao limite da Área de Reprodução Amostral. Para se calcular o desvio padrão é necessário calcular a média aritmética do valor das distâncias entre os pontos de registro. As fórmulas de ambos são:

$$
\text { Média: } \mathrm{x}=\frac{\sum\left(x_{i}\right)}{N_{i}} \quad \text { Desvio-padrão: } \mathrm{s}=\sqrt{\frac{\sum\left(x_{i}-x\right)^{2}}{N-1}}
$$


Quanto às variáveis ambientais utilizadas, escolheram-se aquelas mais importantes para a espacialização do nicho da espécie baseados em referência bibliográfica. Tais variáveis foram divididas em duas categorias, as de adição, cujos atributos favorecem ou diminuem a capacidade da espécie de habitar um local e a de exclusão, aquela que se não ocorrer não permite a sobrevivência da espécie, mesmo que ali ocorram demais variáveis favoráveis à sua sobrevivência e reprodução.

Na matriz geográfica produzida seguiu-se o exposto por Ferreira (1997) em que as células da tabela correspondem a determinado atributo de determinada variável ambiental ocorrente em determinado lugar.

$\mathrm{Na}$ matriz, entendem-se tais células como fatos geográficos. Isso porque segundo Ferreira (1997), Berry e Baker (1968, p. 22) dizem que uma observação registrada do ponto de vista espacial, pode ser denominada de fato geográfico, ou seja, " [...] apenas um de um conjunto de observações, seja da mesma característica de uma série de lugares, seja uma série de características do mesmo lugar [...]" (p. 31).

Todos os atributos de todas as variáveis de adição foram elaborados no Plano de Manejo do PEI de 2008. Foram sobrepostos em formato digital no software de geoprocessamento Spring 5.0.6 (vetores de extensão shape). As unidades resultantes de cada sobreposição correspondem a unidades homogêneas em forma e cobertura quanto aos atributos das variáveis ambientais trabalhadas subdivididos, conforme os propósitos e critérios dos especialistas que as elaboraram para subsidiarem medidas as serem tomadas no Plano de Manejo.

Entretanto, essas unidades homogêneas precisavam ser agrupadas conforme a percepção ambiental da espécie abordada. Cada variável de adição foi dividia em atributos mais e menos favoráveis à reprodução de Carponis melanocephala. Os atributos mais favoráveis foram aqueles ocorrentes na amostra da área de reprodução, enquanto os menos aqueles com valores cada vez mais distantes da área de amostra. Cada atributo de cada variável foi pontuado, valores maiores são mais semelhantes à amostra, enquanto os menores menos semelhantes.

Cada unidade homogênea obtida na sobreposição obteve um conjunto de algarismos correspondentes aos valores dos atributos das variáveis que ali ocorrem. Primeiro foram pontuados os atributos das variáveis mais importantes para a sobrevivência da espécie conforme a bibliografia, depois os das menos importantes. Os conjuntos de 
valores foram ordenados dos iguais ou próximos aos mais distantes da amostra da área de reprodução, sendo os mais próximos representativos de unidades homogêneas com potencial biótico para sobrevivência da espécie, enquanto os mais distantes com potencial menor ou mínimo. Desse modo, muitas unidades começaram a ter valores iguais, podendo ser agrupadas futuramente em grupos de excelente potencial biótico até os de potencial mínimo.

Todas as unidades com distintos potenciais da matriz foram representadas cartograficamente em mapa de espacialização do nicho ecológico da espécie. Este mapa foi comparado à modelagem do nicho da mesma baseada em dados climáticos e de vegetação realizada através de modelo matemático que dimensiona espacialmente os parâmetros ambientais das áreas em que a espécie foi registrada (GILLESPIE et al., 2008). Também foi comparado com a imagem da cobertura da terra do PEI e seu entorno até o PEJ, e com mapas de determinadas unidades de zoneamento para uso e ocupação da terra do PEl e entorno, elaborados para subsidiar ações do Plano de Manejo.

Em tal comparação é que se intentou encontrar evidencias que possam demonstrar a influencia sofrida pelas unidades de paisagens e paisagens obtidas por gradientes universais associados à cadeia de montanhas, fazendo surgir a ocorrência real de regiões a serem identificadas e melhor compreendidas ambientalmente no setor paulista da Serra de Paranapiacaba.

\section{RESULTADOS}

Ao todo, foram obtidos 55 contatos. Cerca de $50 \%$ dos pontos foram obtidos com a técnica do playback, enquanto outros $50 \%$ foram obtidos através do reconhecimento do canto da espécie realizados ao acaso enquanto se caminhava as trilhas.

Para produzir a Área de Reprodução Amostral (Figura 3), espacializou-se os registros da espécie sobre a base cartográfica impressa da carta Taquaral (1974) do IBGE em escala 1:50000. Em seguida, calculou-se o desvio padrão a partir do cálculo da distância entre os pontos, para obter o valor do raio dos círculos traçados, cujos pontos centrais foram cada ponto registrado. 
Na fórmula do desvio padrão, $x_{1}, x_{2}, x_{3} \ldots . . x_{n}$ representam as distâncias em linha reta existentes entre cada ponto (as distâncias foram obtidas em centímetros). Calculou-se a média aritmética das distâncias através da divisão de sua soma pela quantidade das mesmas.

Posteriormente, fez-se a subtração de cada distância menos a média aritmética e elevamos a diferença ao quadrado. Este cálculo é representado pela expressão entre parênteses na fórmula do desvio padrão. Em seguida, dividiu-se a soma de cada expressão entre parênteses pelo número de distâncias obtidas (n) subtraído do número 1. A raiz quadrada do quociente obtido resultou no valor do desvio padrão que foi de 0,946379 centímetros para a base cartográfica em escala 1:50000.

Partes dos círculos se sobrepuseram umas sobre as outras, o limite máximo, ou seja, os limites que não representavam as limitações de áreas sobrepostas, foram concatenados e definidos como os limites da Área de Reprodução Amostral, que em outras palavras, consistiu na soma ou aglutinação da área de todos os círculos circunscritos sobre cada ponto de registro.

Escolheram-se variáveis ambientais representadas nos mapas do Plano de Manejo do PEI (2008) que podem ser associadas à distinção de terras baixas e suas florestas maduras presentes na área do PEI e entorno. Todas as variáveis representam características da paisagem em que ocorrem já que associam características de cobertura e estrutura da mesma: vegetação, clima, geomorfologia e uso da terra. A variáveis, bem como os mapas em que são representadas no Plano de Manejo e os vetores sobrepostos em SIG à quais estão associadas, estão representadas no Quadro 2.

O grau de importância das variáveis, bem como seu papel qualitativo, pode ser observado no Quadro 3. O valor de importância é representado por uma seta que aponta maior valor para o Mapa de Uso da Terra e menor para o Mapa de Compartimentos de Chuva. A variável "Tipo de cobertura da superfície" foi considerada como exclusiva porque define quais áreas são compostas por vegetação florestal (essencial à sobrevivência de Carponis melanocephala em mínimas condições, devido ao fornecimento de microclima que mantém alta umidade e condições climáticas estáveis ao ambiente florestal) e por algum tipo de atividade humana. Sem a cobertura florestal não existe a possibilidade da ave em questão existir, por isso esta 
foi considerada a variável mais importante, desse modo, foi sobreposta por último, após a sobreposição das variáveis de adição.

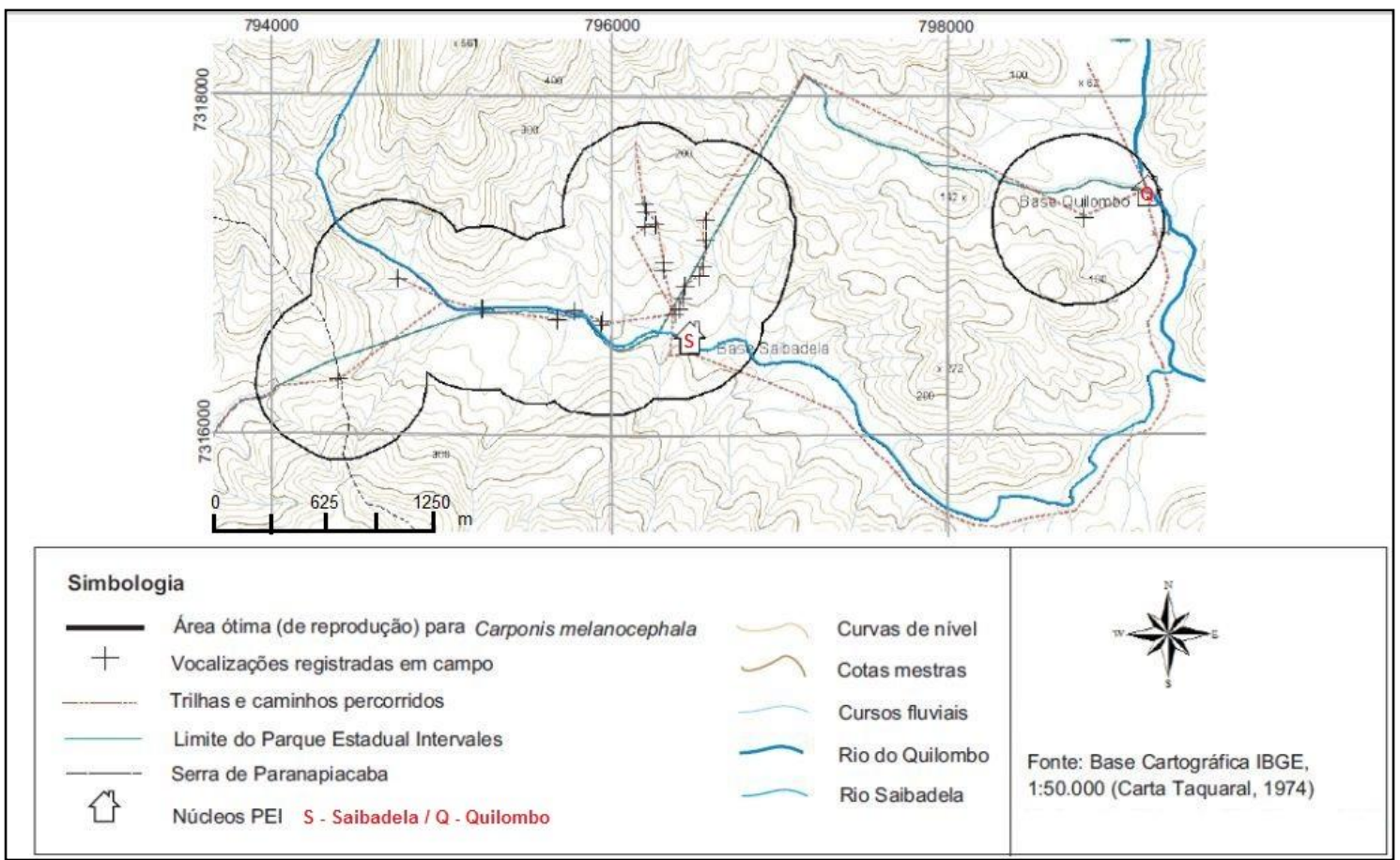

Figura 3: Área de Reprodução Amostral de Carponis melanocephala no PEl. Fonte: Eduardo Silva Bueno, Helga Grigorowitschs - 2009.

\begin{tabular}{|c|c|c|c|c|c|}
\hline & \multicolumn{5}{|l|}{ Mapas } \\
\hline & $\begin{array}{l}\text { Temperatura do } \\
\text { ar }\end{array}$ & Vegetação & $\begin{array}{l}\text { Pluviosidade } \\
\text { Média Anual } \\
\text { (série de } 30 \\
\text { anos) }\end{array}$ & $\begin{array}{l}\text { Compartimentos } \\
\text { de Chuva }\end{array}$ & $\begin{array}{ll}\text { Uso } & \text { da } \\
\text { Terra } & \end{array}$ \\
\hline Vetores & $\begin{array}{l}\text { Limites dos } \\
\text { ambientes } \\
\text { térmicos } \\
\text { definidos por } \\
\text { curvas de nível } \\
\end{array}$ & $\begin{array}{ll}\text { Limites } & \text { das } \\
\text { formações } & \\
\text { vegetais } & \end{array}$ & $\begin{array}{l}\text { Isoietas, } \\
\text { intervalos de } \\
50 \mathrm{~mm}\end{array}$ & $\begin{array}{l}\text { Limites das } \\
\text { unidades } \\
\text { geomorfológicas }\end{array}$ & 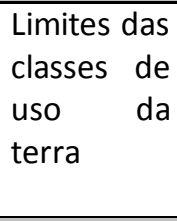 \\
\hline $\begin{array}{l}\text { Variáveis } \\
\text { ambientais }\end{array}$ & $\begin{array}{l}\text { Temperatura } \\
\text { média das } \\
\text { unidades } \\
\text { topoclimáticas }\end{array}$ & $\begin{array}{l}\text { Tipos de } \\
\text { fitofisionomias } \\
\text { florestais }\end{array}$ & $\begin{array}{l}\text { Padrão de } \\
\text { distribuição } \\
\text { de registros } \\
\text { de } \\
\text { pluviosidade }\end{array}$ & $\begin{array}{l}\text { Unidades } \\
\text { geomorfológicas } \\
\text { (morfoescultura e } \\
\text { modelado do } \\
\text { relevo) }\end{array}$ & $\begin{array}{l}\text { Tipo de } \\
\text { cobertura } \\
\text { da } \\
\text { superfície }\end{array}$ \\
\hline
\end{tabular}

Quadro 2 - Mapas e variáveis ambientais utilizados para a espacialização do nicho ecológico de Carponis melanocephala no PEI e entorno

As outras variáveis agem sobre o nicho de Carponis melanocephala adicionando potencial a um local de área florestada, qualificando o mesmo em maior ou menor 
conforme os parâmetros de exigência da espécie definidos pela Área de Reprodução

Amostral.

\begin{tabular}{|c|c|c|c|c|c|}
\hline & \multicolumn{5}{|l|}{ Mapas } \\
\hline & $\begin{array}{l}\text { Compartimentos de } \\
\text { Chuva }\end{array}$ & $\begin{array}{l}\text { Pluviosidade } \\
\text { Média Anual } \\
\text { (série de } 30 \\
\text { anos) }\end{array}$ & Vegetação & $\begin{array}{l}\text { Temperatura } \\
\text { do } \mathrm{Ar}\end{array}$ & $\begin{array}{l}\text { Uso da } \\
\text { Terra }\end{array}$ \\
\hline \multicolumn{6}{|l|}{ Importância } \\
\hline $\begin{array}{l}\text { Papel } \\
\text { qualitativo }\end{array}$ & Adição & Adição & Adição & Adição & Exclusão \\
\hline
\end{tabular}

Quadro 3 - Mapas utilizados, importância e papel qualitativo das variáveis ambientais que representam

As variáveis de adição mais importantes foram aquelas diretamente associadas à identificação de terras baixas e de formações florestais, pois são aquelas mais importantes à reprodução e sobrevivência de Carponis melanocephala. "Temperatura média das unidades topoclimáticas" foi definida como a mais importante porque é aquela que está associada às cotas altimétricas da área de estudo, sendo elaborada em escala de detalhe (topoclimática). "Tipos de fitofisionomias florestais" a segunda porque corresponde à vegetação, e representa os tipos de vegetação mais e menos associados às terras baixas do PEI e entorno. Já "Padrão de distribuição de registros de pluviosidade" e "Unidades geomorfológicas (morfoescultura e modelado do relevo)", foram tratadas como menos importantes porque não estão associadas diretamente à identificação de terras baixas e vegetação, mas sim à distancia do mar e morfoescultura do relevo respectivamente, sendo obtidas em análises realizadas em escalas menos detalhadas.

Os atributos de cada variável de adição trabalhada são representados no Quadro 4.

Aplicando o exposto por Delpoux (1974) as variáveis 1, 2 e 3 representam a cobertura, a 4 o suporte. Segundo Bertrand (1971) as variáveis 1, 3 e 4 o elemento físico, a 2 o biológico. A variável de exclusão representa a cobertura para o primeiro e o elemento antrópico no segundo.

Na coluna "Potenciais bióticos" da matriz geográfica, os números em negrito, sublinhados e em itálico, indicam o valor de determinada variável responsável pela principal característica da unidade de paisagem a que está associado. Esses números, em linhas gerais, refletem a mudança gradual na escala de cores existente na coluna 
"Classes de potencialidade", por fim, essa mudança gradual corresponde na coluna

"Agrupamentos de classes", a agrupamentos de unidades de paisagem que podem ser

feitos conforme as semelhanças existentes entre as mesmas.

\begin{tabular}{|c|c|c|c|c|c|}
\hline & \multicolumn{4}{|l|}{ Valor dos atributos } & \multirow{4}{*}{ 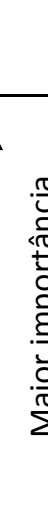 } \\
\hline & 1 & 2 & 3 & 4 & \\
\hline $\begin{array}{l}\text { Variável } 1 \\
\text { Temperatura média } \\
\text { das unidades } \\
\text { topoclimáticas } \\
\end{array}$ & $>800$ metros & $\begin{array}{l}\text { Entre } 400 \text { e } 800 \\
\text { metros }\end{array}$ & $<400$ metros & & \\
\hline $\begin{array}{l}\text { Variável } 2 \\
\text { Tipos de } \\
\text { fitofisionomias } \\
\text { florestais }\end{array}$ & $\begin{array}{lr}\text { Vegetação } & \text { com } \\
\text { influência } & \text { de } \\
\text { florestas } & \text { de } \\
\text { araucárias } & \\
\text { (Araucária } & \\
\text { angustifólia) } & \end{array}$ & $\begin{array}{l}\text { Fitofisionomias } \\
\text { relacionadas ao tipo } \\
\text { de solo e ação } \\
\text { antrópica (florestas } \\
\text { de várzeas, abertas } \\
\text { ou de bambus) }\end{array}$ & $\begin{array}{l}\text { Vegetação } \\
\text { relacionada a } \\
\text { gradiente } \\
\text { altitudinal }\end{array}$ & & \\
\hline $\begin{array}{ll}\text { Variável 3 } & \\
\text { Padrão } & \text { de } \\
\text { distribuição } & \text { de } \\
\text { registros } & \text { de } \\
\text { pluviosidade } & \end{array}$ & $\begin{array}{l}\text { Áreas a oeste da } \\
\text { isoieta } 1550 \mathrm{~mm}\end{array}$ & $\begin{array}{l}\text { Áreas a oeste da } \\
\text { isoieta } 1600 \mathrm{~mm}\end{array}$ & $\begin{array}{l}\text { Áreas a oeste } \\
\text { da isoieta } \\
1650 \mathrm{~mm}\end{array}$ & $\begin{array}{l}\text { Áreas entre } \\
\text { os limites } \\
\text { do Entorno } \\
\text { PEI e a } \\
\text { isoieta } \\
1650 \mathrm{~mm}\end{array}$ & \\
\hline $\begin{array}{l}\text { Variável } 4 \\
\text { Unidades } \\
\text { geomorfológicas } \\
\text { (morfoescultura e } \\
\text { modelado do } \\
\text { relevo) }\end{array}$ & $\begin{array}{ll}\text { Planalto } & \text { de } \\
\text { Guapiara } & \end{array}$ & $\begin{array}{l}\text { Serra de } \\
\text { Paranapiacaba e } \\
\text { Depressão Tectônica } \\
\text { do Vale do Ribeira }\end{array}$ & & & 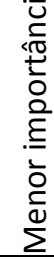 \\
\hline & Maior potencial & & & tor potencial & \\
\hline
\end{tabular}

Quadro 4 - Valores qualitativos de cada variável de adição conforme comparação com a Área de Reprodução Amostral

Ao reconhecer os padrões desses números e compará-los à divisão exata de um gradiente cromático pelo número total de classes obtidas, pode-se identificar e reconhecer as características ambientais de cada grupo e criar uma legenda que possa ser representada cartograficamente (Quadros 5 e 6). Entende-se então que esses grupos correspondem a paisagens.

As classes de potencialidade da matriz geográfica são representadas cartograficamente na Figura 4. Pode-se observar nesta figura que existe uma brusca divisão através de um limite em linha diagonal que separa uma área de tonalidade laranja escuro de um laranja claro mais próximo do amarelo. Esta divisão se mostra muito evidente nas terras intermediárias (altitude entre 400 e 800 metros), majoritariamente representada pelos tons laranja. Nas terras baixas (vermelho) ela é bem menos evidente e nas altas (verde) não ocorre (as flechas da Figura 4 apontam a localização 
desta divisão). Está associada ao delineamento da isoieta $1650 \mathrm{~mm}$ que separa as áreas de atributo valor 3 e 4 da variável "Padrão de distribuição de registros de pluviosidade" (Quadro 4). Outras divisões associadas às demais isoietas também existem, mas muito menos evidentes que aquela associada à isoieta $1650 \mathrm{~mm}$.

\begin{tabular}{|c|c|c|c|c|c|}
\hline & \multicolumn{5}{|c|}{ Agrupamentos ou paisagens } \\
\hline & $\begin{array}{l}\text { Excelente } \\
\text { potencial }\end{array}$ & $\begin{array}{l}\text { Bom } \\
\text { potencial }\end{array}$ & $\begin{array}{l}\text { Potencial } \\
\text { intermediário }\end{array}$ & $\begin{array}{l}\text { Baixo } \\
\text { potencial }\end{array}$ & $\begin{array}{l}\text { Potencial } \\
\text { mínimo }\end{array}$ \\
\hline Cotas $<400$ metros & $\mathrm{x}$ & & & & \\
\hline $\begin{array}{l}\text { Cotas entre } 400 \text { e } 800 \\
\text { metros }\end{array}$ & & $\mathrm{x}$ & & & \\
\hline $\begin{array}{l}\text { Cotas entre } 400 \text { e } 800 \\
\text { metros } \\
\text { fitofisionomias } \\
\text { relacionadas ao tipo } \\
\text { de solo e ação } \\
\text { antrópica }\end{array}$ & & & $\mathrm{x}$ & & \\
\hline $\begin{array}{l}\text { Cotas entre } 400 \text { e } 800 \\
\text { metros + florestas de } \\
\text { Araucária (Araucaria } \\
\text { angustifólia) e cotas } \\
>800 \text { metros + } \\
\text { vegetação relacionada } \\
\text { a gradiente altitudinal }\end{array}$ & & & & $\mathrm{x}$ & \\
\hline $\begin{array}{l}\text { Cota }>800 \text { metros }+ \\
\text { fitofisionomias } \\
\text { relacionadas ao tipo } \\
\text { de solo e vegetação } \\
\text { antrópica e cota }>800 \\
\text { metros + florestas } \\
\text { Araucária (Araucaria } \\
\text { angustifólia) }\end{array}$ & & & & & $\mathrm{x}$ \\
\hline
\end{tabular}

Quadro 5 - Características ambientais dos agrupamentos de classes obtidos

Ao observar-se os Quadros 5 e 6, percebe-se que as unidades que mais se destacam no mapa da Figura 4 estão fortemente associadas a diferenças de um gradiente altitudinal (vermelho nas terras baixas, laranja e amarelo nas intermediárias e verde nas altas). $\mathrm{Na}$ área a leste da isoieta $1650 \mathrm{~mm}$, ocorre uma transição mais estreita da cor vermelha para a verde, a cor laranja é mais escura, muito parecida com o tom vermelho e sua área consiste numa faixa estreita e alongada (na Figura 1, em linhas gerais, observa-se que parece ocorrer aí um padrão de rugosidade do relevo característico de área de escarpa, ou seja, uma transição abrupta entre terras baixas e altas). Já na área a oeste da isoieta $1650 \mathrm{~mm}$, o tom laranja é mais claro, muito próximo de um amarelo escuro, possuindo uma faixa mais larga e ampla que 
representa a transição entre o tom vermelho e o verde (na Figura 1, em linhas gerais, observa-se que parece ocorrer aí um padrão de rugosidade dado em patamares, onde não há escarpa, mas, em linhas gerais, um tipo de relevo associado a cada faixa altitudinal representada pelas terras baixas, intermediárias e altas).

\begin{tabular}{|c|c|c|c|c|c|c|c|c|}
\hline & \multicolumn{4}{|c|}{$\begin{array}{l}\text { Variáveis ambientais } \\
\text { (segundo Quadro 4) }\end{array}$} & \multirow[b]{2}{*}{$\begin{array}{l}\text { Potenciais } \\
\text { bióticos }\end{array}$} & \multirow[b]{2}{*}{$\begin{array}{l}\text { Classes de } \\
\text { potencialidade }\end{array}$} & & \multirow[b]{2}{*}{$\begin{array}{l}\text { Agrupamentos } \\
\text { de classes }\end{array}$} \\
\hline & \multirow{2}{*}{\begin{tabular}{|l|}
1 \\
3 \\
\end{tabular}} & \multirow{2}{*}{$\begin{array}{l}2 \\
3\end{array}$} & \multirow{2}{*}{\begin{tabular}{|c|}
3 \\
4
\end{tabular}} & \multirow{2}{*}{$\begin{array}{r}4 \\
2\end{array}$} & & & & \\
\hline \multirow{44}{*}{ 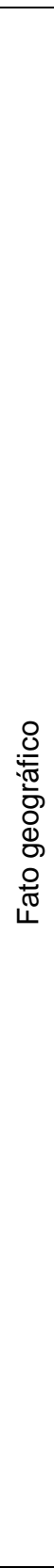 } & & & & & 3342 & Vermelho & $\square$ & \multirow{6}{*}{$\begin{array}{l}\text { Excelente } \\
\text { potencial }\end{array}$} \\
\hline & 3 & 3 & 3 & 2 & 3332 & Vermelho & $\bar{\square}$ & \\
\hline & 3 & 3 & 2 & 2 & 3322 & Vermelho & $\square$ & \\
\hline & 3 & 2 & 4 & 2 & $3 \underline{2} 42$ & Vermelho laranja & $\square$ & \\
\hline & 3 & 2 & 3 & 2 & 3232 & Vermelho laranja & $\square$ & \\
\hline & 3 & 2 & 2 & 2 & 3222 & Vermelho Iaranja & $\square$ & \\
\hline & 2 & 3 & 4 & 2 & 2342 & Chocolate & $\square$ & \multirow{5}{*}{ Bom potencial } \\
\hline & 2 & 3 & 4 & 1 & 2341 & Laranja escuro & $\square$ & \\
\hline & 2 & 3 & 3 & 2 & $23 \underline{3} 2$ & Laranja escuro & $\square$ & \\
\hline & 2 & 3 & 3 & 1 & $23 \underline{31}$ & Laranja escuro & $\square$ & \\
\hline & 2 & 3 & 2 & 2 & $23 \overline{2} 2$ & Laranja escuro & $\square$ & \\
\hline & 2 & 3 & 2 & 1 & 2321 & Ouro & $\square$ & \multirow{9}{*}{$\begin{array}{c}\text { Potencial } \\
\text { Intermediário }\end{array}$} \\
\hline & 2 & 3 & 1 & 1 & $23 \underline{11}$ & Ouro & $\square$ & \\
\hline & 2 & 2 & 4 & 2 & 2242 & Amarelo & $\square$ & \\
\hline & 2 & 2 & 4 & 1 & $2 \underline{2} 41$ & Amarelo & $\bar{\square}$ & \\
\hline & 2 & 2 & 3 & 2 & 2232 & Amarelo & $\square$ & \\
\hline & 2 & 2 & 3 & $\frac{2}{1}$ & $2 \underline{2} 31$ & Amarelo & $\square$ & \\
\hline & 2 & 2 & 2 & 2 & 2222 & Amarelo & $\square$ & \\
\hline & 2 & 2 & 2 & 1 & 2221 & Amarelo & $\square$ & \\
\hline & 2 & 2 & 1 & 1 & 2211 & Dourado & $\square$ & \\
\hline & 2 & 1 & 3 & 2 & 2132 & Dourado & $\square$ & \multirow{14}{*}{ Baixo potencial } \\
\hline & 2 & 1 & 3 & 1 & 2131 & Lima & $\square$ & \\
\hline & 2 & 1 & 2 & 2 & 2122 & Lima & $\bar{\square}$ & \\
\hline & 2 & 1 & 2 & 1 & 2121 & Lima & $\bar{\square}$ & \\
\hline & 2 & 1 & 1 & 1 & $2 \overline{1111}$ & Lima & $\square$ & \\
\hline & 1 & 3 & 4 & 2 & 1342 & Lima & $\square$ & \\
\hline & 1 & 3 & 4 & 1 & 1341 & Lima & $\square$ & \\
\hline & 1 & 3 & 3 & 2 & 1332 & Lima & $\square$ & \\
\hline & 1 & 3 & 3 & 1 & 1331 & Lima & $\square$ & \\
\hline & 1 & 3 & 2 & 2 & 1322 & Lima & $\square$ & \\
\hline & 1 & 3 & 2 & 1 & 1321 & Lima & $\square$ & \\
\hline & 1 & 3 & 1 & 1 & 1311 & Lima & $\square$ & \\
\hline & 1 & 2 & 4 & 2 & 1242 & Lima & $\square$ & \\
\hline & 1 & 2 & 4 & 1 & 1241 & Lima & $\square$ & \\
\hline & 1 & 2 & 3 & 2 & $\overline{12} \underline{32}$ & Verde mar claro & $\square$ & \multirow{10}{*}{$\begin{array}{l}\text { Potencial } \\
\text { mínimo }\end{array}$} \\
\hline & 1 & 2 & 3 & 1 & $12 \overline{\mathbf{3}} \mathbf{1}$ & Verde mar claro & $\square$ & \\
\hline & 1 & 2 & 2 & 2 & 1222 & Turquesa escura & $\square$ & \\
\hline & 1 & 2 & 2 & 1 & $12 \underline{2} 1$ & Turquesa escura & $\square$ & \\
\hline & 1 & 2 & 1 & 1 & 1211 & Turquesa escura & $\bar{\square}$ & \\
\hline & 1 & 1 & 3 & 2 & 1132 & Turquesa escura & $\bar{\square}$ & \\
\hline & 1 & 1 & 3 & 1 & $1 \underline{131}$ & Água & $\square$ & \\
\hline & 1 & 1 & 2 & 2 & $1 \underline{12} 2$ & Água & $\square$ & \\
\hline & 1 & 1 & 2 & 1 & 1121 & Água & $\square$ & \\
\hline & \multirow{2}{*}{\multicolumn{4}{|c|}{\begin{tabular}{|c|c|c|}
1 & 1 & 1 \\
Fato geográfico
\end{tabular}}} & $1 \overline{111}$ & Água & $\square$ & \\
\hline & & & & & & & & \\
\hline
\end{tabular}

Quadro 6- Matriz geográfica 
Sabendo-se que as principais cores e rugosidades observadas respectivamente nas Figuras 4 e 1 representam faixas altitudinais que correspondem majoritariamente a unidades topoclimáticas (variável 1 do Quadro 4), constata-se que existe a leste da isoieta $1650 \mathrm{~mm}$ um relevo mais íngreme em que o gradiente altitudinal da Serra de Paranapiacaba é mais acentuado, ou seja, a mudança das altitudes se dá em pequena distância horizontal. Já a oeste da isoieta 1650 mm, a transição das cotas mais baixas para as mais altas se dá de forma gradual, ou seja, numa distância horizontal mais extensa. Quando se sobrepõe o mapa do nicho ecológico (Figura 4) com a modelagem obtida a partir de simulações matemáticas (Figura 5), verificamos que essa divisão pode representar a existência de dois padrões ambientais, um a leste e outro a oeste da isoieta $1650 \mathrm{~mm}$. 


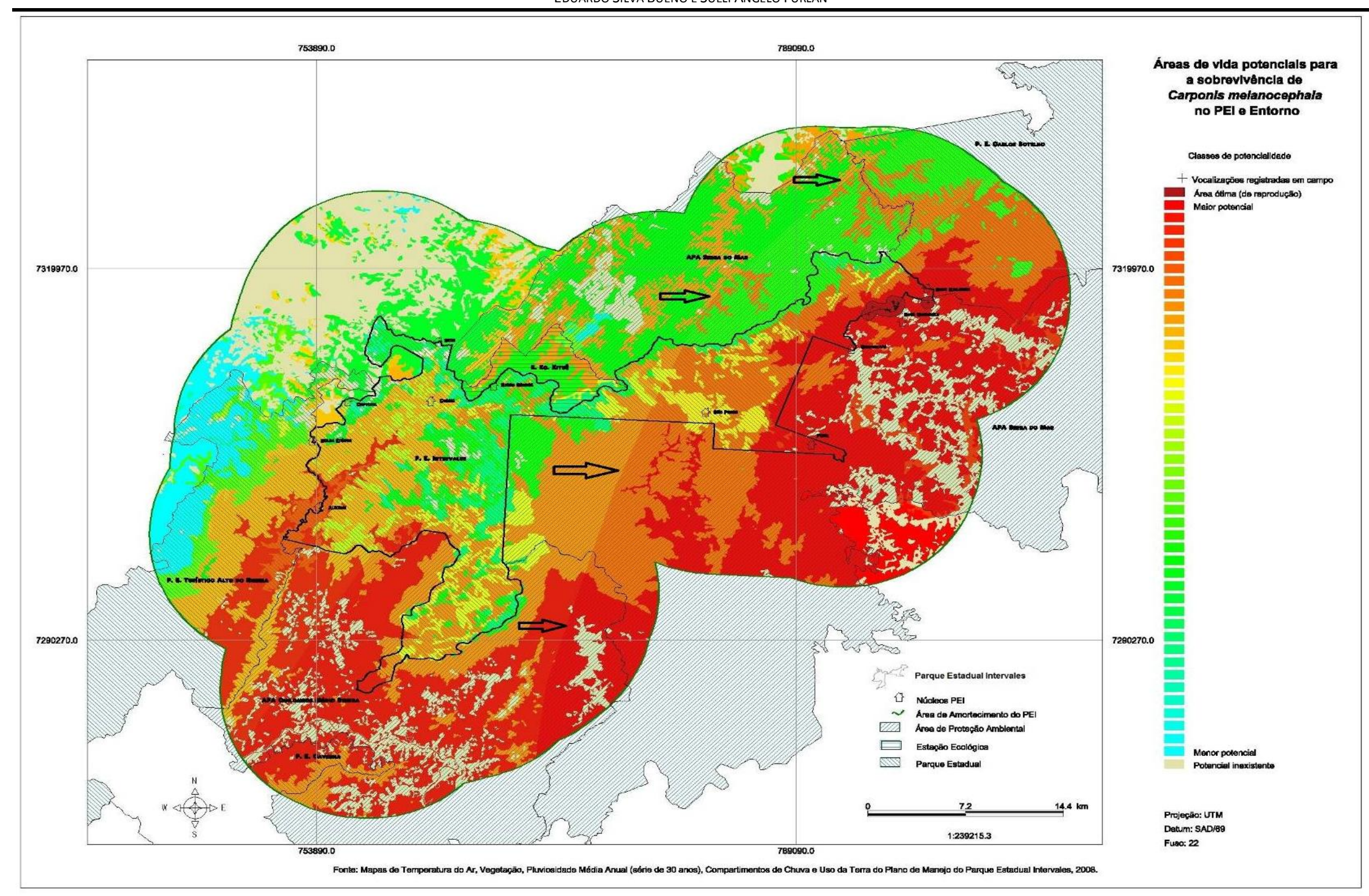

Figura 4: Espacialização do nicho ecológico de Carponis melanocephala para o PEl e entorno. Fonte: Eduardo Silva Bueno - 2009. 
Observou-se na Figura 5 que a divisão entre os setores de pixels vermelhos e laranjas (linha amarela), em linhas gerais, coincide melhor com a isoieta $1650 \mathrm{~mm}$ do que com as de mais, principalmente nos limites do PEI e entorno.

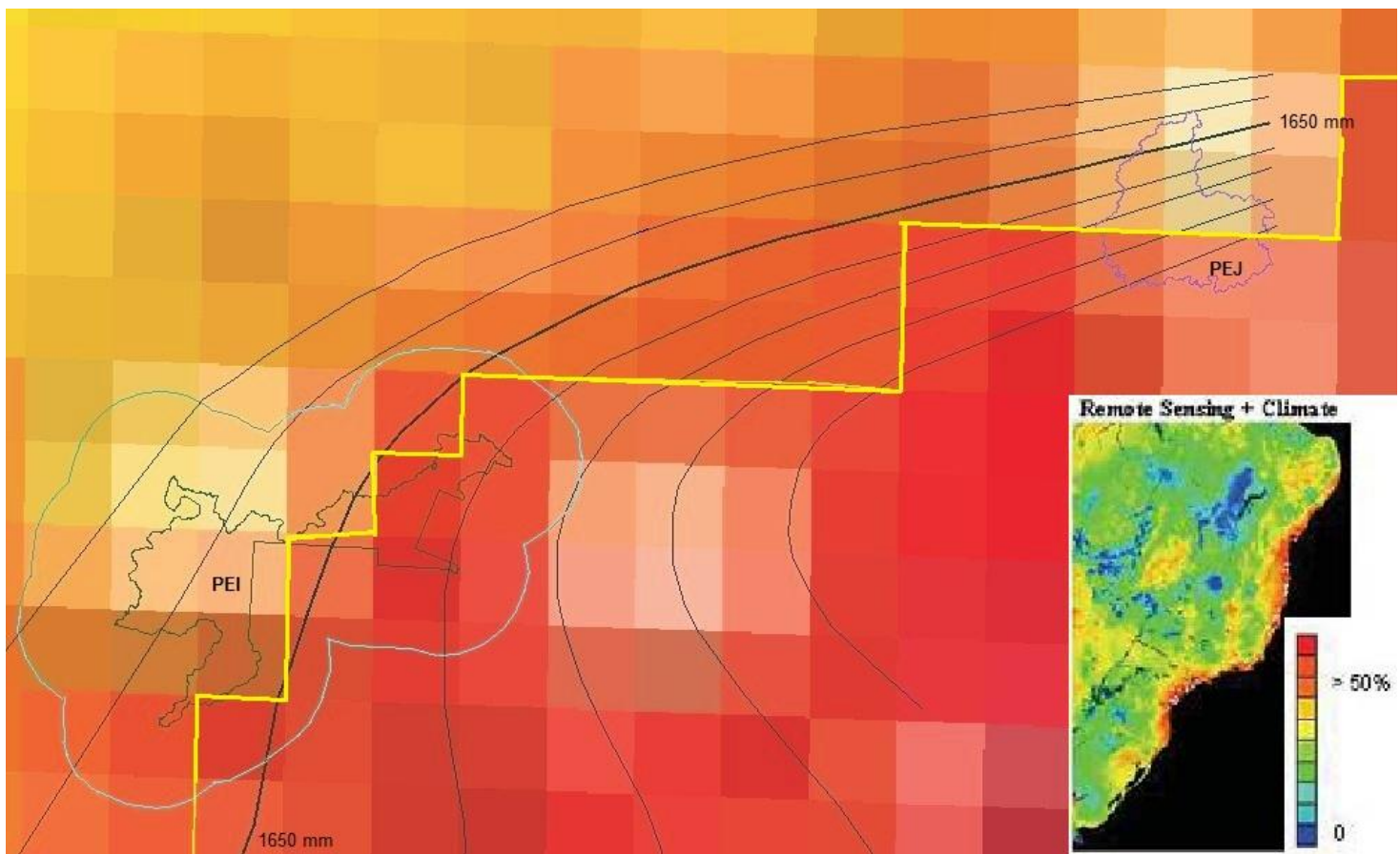

Figura 5: Modelagem de nicho ecológico de Carponis melanocephala para o PEl e entorno e Brasil. Fonte: Gillespie et al. (2008). Adaptação: Eduardo Silva Bueno - 2009.

Conforme o método elaborado, sabendo-se que as paisagens de terras baixas da encosta atlântica sudeste brasileira podem se expandir para as médias encostas e até para as altas encostas, criando ambiente propício para a existência de espécies frutíferas consumidas por Carponis melanocephala, elaboramos um modelo de como esse fenômeno pode ocorrer, sugerindo uma explicação da ocorrência da espécie no PEJ (Figura 6). 


\section{Perfil Quilombo (encosta mais ingreme)}

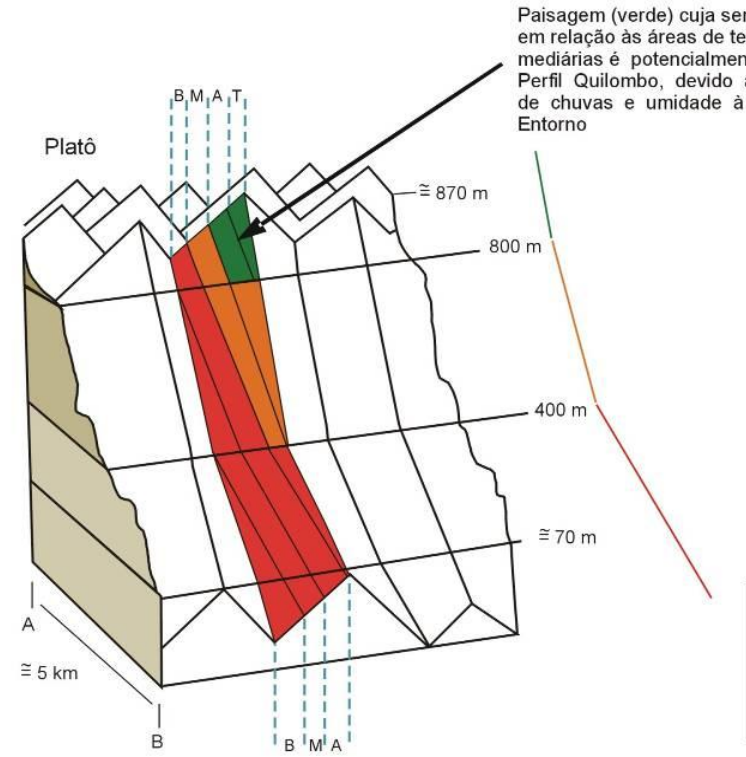

Perfil Mirante-Sede/Calha Pilões (encosta menos íngreme)

Em ambos perfis, a distribuição das paisagens ao longo da e topo de morro Nas baixas da paisagem das terras baixas

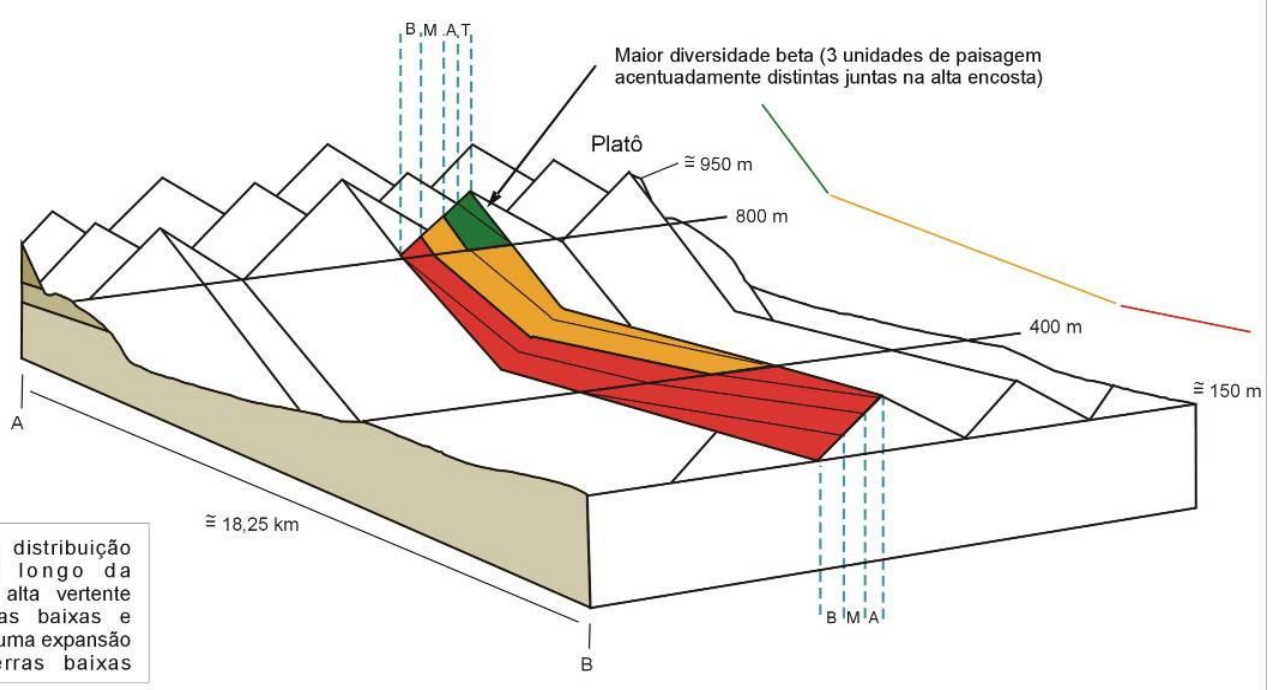

Paisagem das terras baixas

Paisagem das terras intermediárias

Paisagem das terras alta

Distribuiçâo das paisagens ao longo da

- Paisagem de baixa encosta

- Paisagem de média encosta

B: baixa vertente

M: média vertente

A: alta vertente

Média e alta encosta são mais semelhantes à baixa encosta, maior expansão das erras baixas em direção às terras altas devido a semelhança microclimática

(cores semelhantes entre si).

Escalas:

Altitude: $1 \mathrm{~cm} \cong 38,8 \mathrm{~m}$

B: $1 \mathrm{~cm} \cong 1,6 \mathrm{~km}$

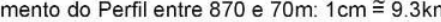
Fonte: Perfil Longitudinal do Rio Quilombo. Plano de Manejo do Parque

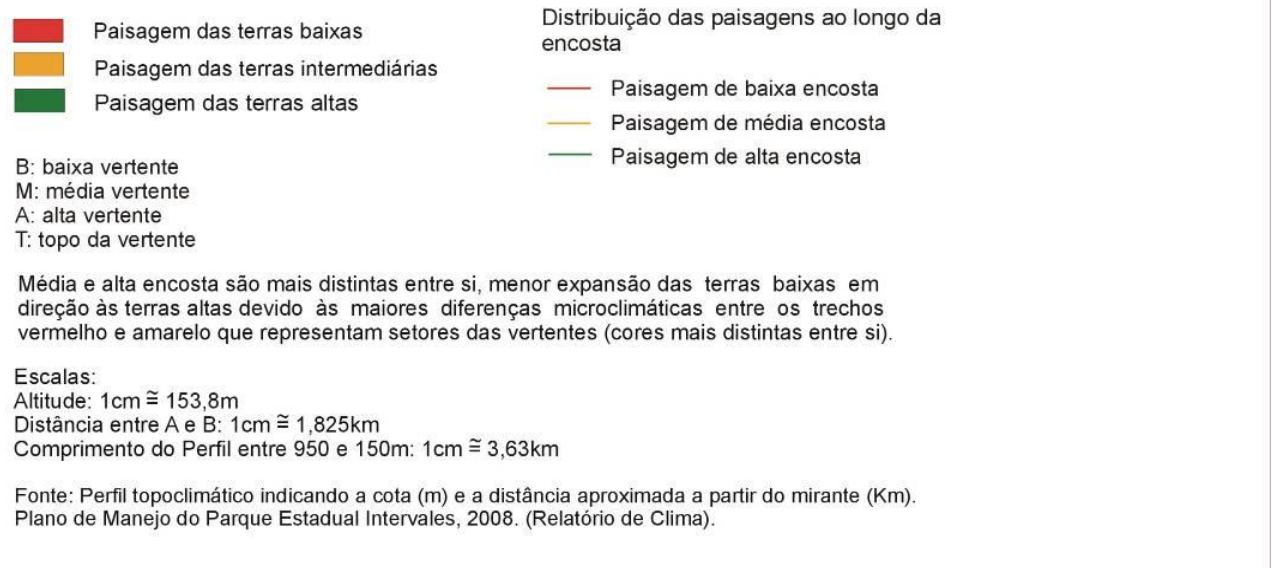

Figura 6: Distribuição das paisagens dadas nas topossequências das vertentes ao longo de setores da encosta atlântica. Elaboração: Eduardo Silva Bueno, Helga Grigorowitschs - 2009 
Nesta figura, os padrões regionais leste e oeste identificados são representados respectivamente pelos perfis longitudinal Rio Quilombo e topoclimático Mirante-Sede/Calha Pilões, ambos estão associados ao vale de rios que descem a encosta das terras altas às baixas da mesma ${ }^{4}$. Foram analisados sob a relação de seus respectivos gradientes altitudinais e distância horizontal em linha reta entre seu ponto mais alto e mais baixo.

A Figura 7 demonstra a localização de ambos os perfis e o delineamento da isoieta $1650 \mathrm{~mm}$ sobre o mapa produzido (Figura 4).

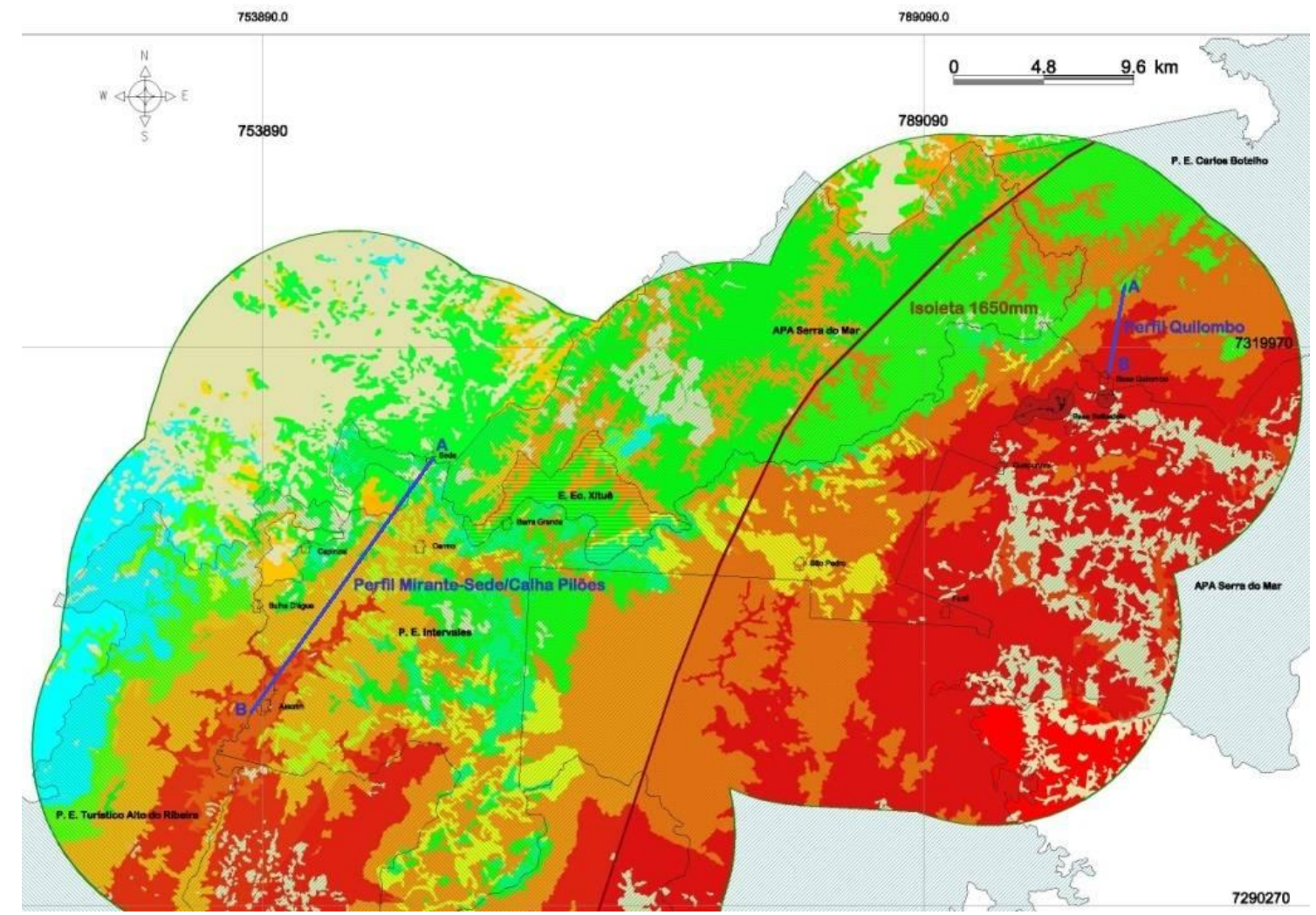

Figura 7: Localização dos perfis Quilombo e Mirante-Sede/Calha Pilões e isoieta $1650 \mathrm{~mm}$ no PEl e entorno. Fonte: Bases digitais do Plano de Manejo do PEI. Elaboração: Eduardo Silva Bueno - 2009.

Em serras de tabuleiros, cujo gradiente altitudinal muda de forma progressiva da costa para o interior, a mudança de chuvas ocorre de forma gradual, isso permite que a vegetação das terras baixas penetre mais para o interior através dos vales dos rios, fazendo uma transição mais gradual das florestas ombrófilas para as semidecíduas (OLIVEIRA FILHO; FONTES, 2000). No Sudeste, onde ocorre a Serra de Paranapiacaba, de um modo geral, a transição florestas ombrófilas/semidecíduas ocorre de forma abrupta, entretanto, no PEI e entorno, ao que parece, de forma mais gradual a oeste da isoieta $1650 \mathrm{~mm}$ e mais abrupta a leste.

\footnotetext{
${ }^{4}$ Ambos os perfis foram utilizados em estudos de hidrografia/geomorfologia fluvial e clima elaborados no Plano de Manejo do PEI, 2008.
} 
É na área leste que a vegetação de terras baixas possui maior potencial para penetrar mais para as terras altas devido à pequena distância horizontal do gradiente altitudinal, mas é na área a oeste, devido ao relevo mais gradual, que ela penetra mais em direção ao interior através dos vales dos rios, pois a distância entre o trecho de terras baixas a altas é maior, como verificado na figura $16(18,25 \mathrm{~km})$. Sabendo-se que o relevo do setor oeste demonstra uma transição mais gradual, ao que parece em patamares de altitude que no setor leste se dá por paredão de serra, conclui-se que no oeste ocorre fenômeno análogo ao das serras de tabuleiros, de alguma forma tais patamares podem se comportar de forma semelhante aos tabuleiros.

Na Figura 6, percebeu-se que a coloração do agrupamento de unidades de paisagem de terras intermediárias é diferente conforme a localidade dos perfis (Figura 7).

Isso parece evidenciar o fato de que a isoieta $1650 \mathrm{~mm}$ representa um limiar em que a leste dela a vegetação de altitude intermediária (laranja escuro) é mais semelhante à das terras baixas do que a oeste (laranja amarelado), mostrando que a vegetação das terras intermediárias é mais ou menos semelhante à das terras baixas conforme o índice de pluviosidade, ou seja, quanto mais distante do mar, mais diferente é a vegetação das terras intermediárias em relação à das terras baixas. Desse modo, constata-se que as paisagens das terras intermediárias a oeste da isoieta $1650 \mathrm{~mm}$ correspondem a uma área de vegetação mais representativa e característica das florestas das áreas intermediárias que a leste.

No Perfil Quilombo se observa uma abrupta transformação das paisagens que de muito semelhantes nas vertentes da baixa e média encosta (vermelho e laranja avermelhado), passam a ser mais diferentes na alta vertente da alta encosta (verde). No Perfil MiranteSede/Calha Pilões a média encosta representa melhor a transição entre baixa e alta encosta. Entretanto, Veloso e Klein (1959) dizem que, floristicamente, as altas encostas de ambientes mais úmidos são mais semelhantes às médias encostas em detrimento de uma identidade florística própria. Em ambientes menos úmidos, como o lado oeste da isoieta $1650 \mathrm{~mm}$, devido à maior distância do mar e maior gradiente horizontal da serra que dificulta a ascensão rápida das massas de ar gerando menos chuvas orográficas, ao que parece, ocorre - contrário, a vegetação da alta encosta possui identidade florística própria, se diferenciando mais da vegetação da média e baixa encosta.

Nota-se então, que na alta vertente do setor a oeste da isoieta $1650 \mathrm{~mm}$ (Perfil MiranteSede/Calha Pilões) é que podem ocorrer unidades de paisagem mais características de cada 
setor da encosta da Serra de Paranapiacaba. Em outras palavras, esses locais são os que mais possuem potencialidade para abrigar em suas vertentes, paisagens bem características dos três principais setores da encosta, devendo ser preservados para garantir a existência de áreas com potencial para abrigar a diversidade associada ao gradiente ambiental da Serra do Mar.

A diversidade beta na encosta atlântica está relacionada ao gradiente ambiental, fundo de vale até alta vertente (ALMEIDA-SCCABBIA, 1996) e à relação dos compartimentos da encosta entre si (SIMONETTI, 2001), ou seja, nas semelhanças e diferenças entre as paisagens que se distribuem ao longo das vertentes que compõe os setores da encosta. Modelos de predição de índices de riqueza de espécie como Ad Hoc Model e Contemporany Climatic Model postulam que a precipitação é a variável que melhor prediz a riqueza de espécies em escala detalhada (RAHBEK; GRAVES, 2001). Desse modo, acredita-se que a geodiversidade na área de estudo pode ser mais bem identificada pela pluviosidade.

Sabendo-se que existe um gradiente climático na Mata Atlântica atuante conforme a distância do mar e a altitude, e sabendo-se que a amplitude altitudinal nos perfis Quilombo e Mirante-Sede/Calha Pilões é parecida, acredita-se que na Serra de Paranapiacaba, o fator que melhor responde às características do clima regional é a pluviosidade. Esta é a que melhor responde à influência do mar continente adentro e à influência dos diferentes setores da morfoescultura, ou modelado geral da Província Costeira ou Serra de Paranapiacaba. Dessa forma, influi nas condições ambientais a que estão relacionados o gradiente de paisagens identificado a leste e oeste.

Como o visto nos perfis (Figura 6), existe uma diferença na distribuição das paisagens relacionadas ao gradiente altitudinal nesses dois perfis, ou seja, a isoieta $1650 \mathrm{~mm}$ não representa só a influência de um clima regional, mas seu limiar demonstra também a influência da pluviosidade na particularidade, ou seja, na característica das paisagens distribuídas nos distintos setores da encostas através das distintas parte partes das vertentes.

Como se pode observar na Figura 8, as áreas a leste da isoieta 1650 mm são protegidas pelos Parques Estaduais Intervales (PEI), Carlos Botelho (PECB) e Jurupará (PEJ), havendo ainda o Corredor Jurupará (CJ) entre os dois últimos parques.

As áreas a oeste da isoieta $1650 \mathrm{~mm}$ estão parcialmente protegidas pelas UCs. Sabendo-se que o Entorno do PEI não corresponde a uma UC, sendo uma Zona de Amortecimento, 
verifica-se que a área da Serra de Paranapiacaba que possui maior potencial para abrigar diversidade beta em sua alta encosta (indicadas pelas setas amarelas na figura 8), estão em sua maior parte contidas no entorno PEI abrigadas pela APA Serra do Mar (ASM na Figura 8) (áreas verdes a oeste da isoieta $1650 \mathrm{~mm}$, ver Figura 7).

Desse modo, o que se verifica é que os limites dos Parques não protegem as áreas que tem maior potencial para abrigar diversidade beta mais concentrada, os mesmos protegem mais as áreas de alto declive onde a Serra de Paranapiacaba se dá em forma de paredão de serra, em relevo mais escarpado.

Como a nordeste do PEl até o PEJ as áreas acima da isoieta $1650 \mathrm{~mm}$ estão quase tomadas pelo perímetro urbano, consideram-se as áreas de terras altas a oeste de tal isoieta do entorno PEI como essenciais à preservação de áreas potencialmente ricas em diversidade beta da Floresta Ombrófila Densa de Província Costeira.

Isso porque a oeste do entorno (Parque Estadual Turístico do Alto Ribeira, PETAR na Figura 8) a paisagem das terras altas muda gradativamente para Floresta Ombrófila Mista, deixando de ter característica de Floresta Ombrófila Densa (Figura 4).

Observando a Figura 4, nas reservas ao sul do PEl, como pôde ser observado em trechos da APA Quilombo Médio Ribeira (AQMR na Figura 8) e Parque Estadual Caverna (PEC na Figura 8), ou há áreas de terras mais baixas com uso intensivo da terra como no primeiro caso, ou as terras mais altas não alcançam áreas superiores a 800 metros para se dizer que ali ocorra potencial para maior concentração de diversidade beta.

Ao se comparar as Figuras 7 e $9 \mathrm{ZI}$ observa-se que no setor leste da isoieta $1650 \mathrm{~mm}$ a área de escarpa protegia pelo PEI é denominada Zona Intangível, assim como parte isolada do setor oeste que também deve representar um testemunho de escarpa em área onde predomina relevo de patamares, pois o setor principal de escarpa na área de estudo é representado pela escarpa do setor leste que continua em direção ao PECB. Na Figura 7 observamos que ambas as áreas de Zonas Intangíveis correspondem a trechos em que as cores vermelho, laranja/amarelo e verde se aproximam, evidenciando a alta amplitude altitudinal dessas áreas (indício de paredão).

Ao se observar a Figura 8, as flechas amarelas que correspondem às áreas verdes situadas a oeste da isoieta $1650 \mathrm{~mm}$ (ver Figura 7), percebe-se que a área que se considera primordial para a preservação da diversidade beta na Serra de Paranapiacaba, coincide em linhas gerais 
com ás Áreas de Interesse à Conservação da Biodiversidade definidas no Relatório de Zoneamento do Plano de Manejo do PEI (2008) (figura 9AICB).

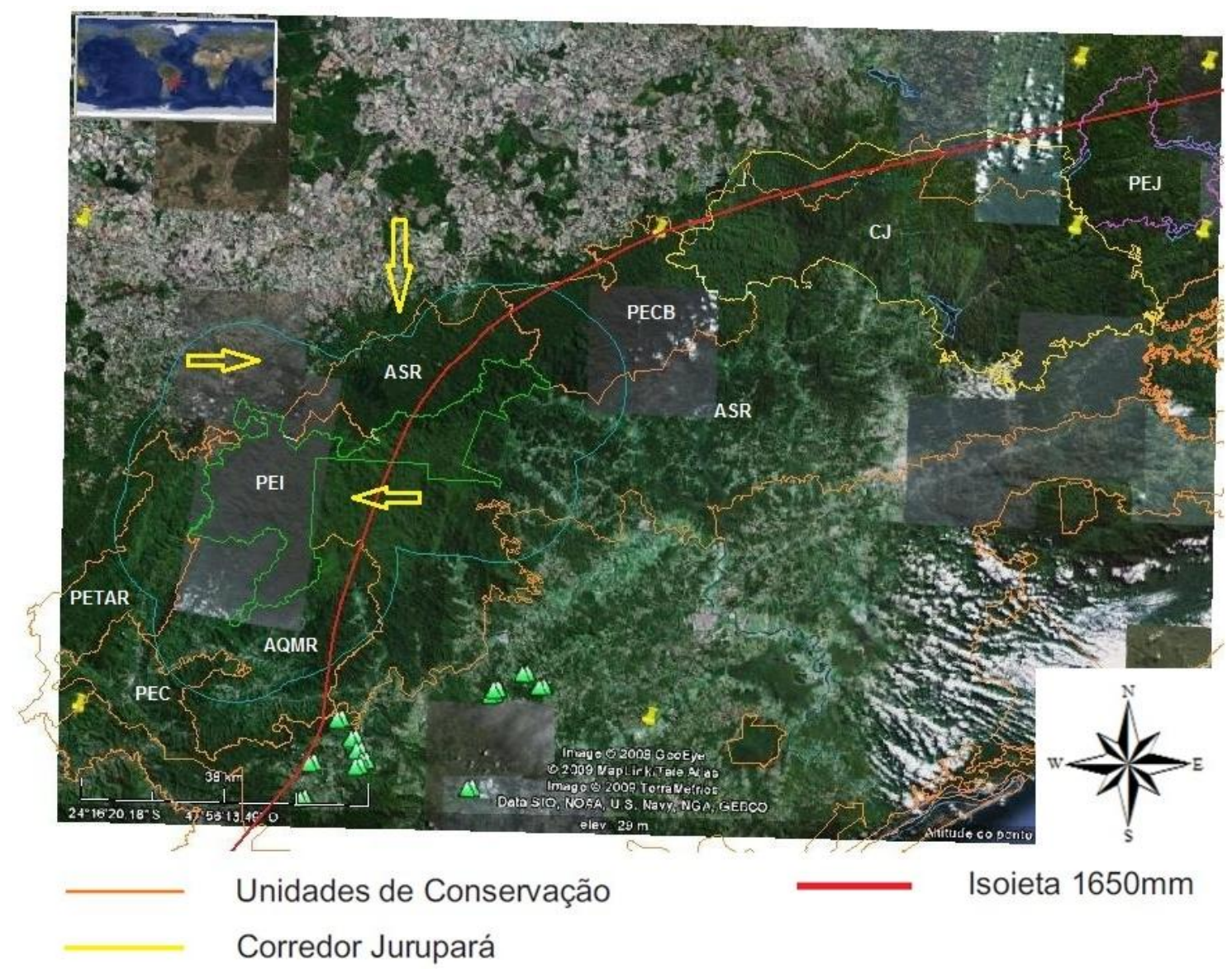

Figura 8: Unidades de Conservação no Contínuo Ecológico de Paranapiacaba, área entre PEI e PJ. Fonte: Google Earth (2008), bases digitais do Plano de Manejo do PEI (2008). Elaboração: Eduardo Silva Bueno - 2009.

As Áreas de Interesse à Conservação da Biodiversidade são as áreas mais importantes na setorização da Zona de Amortecimento do PEl, como se fossem as áreas de Zona Intangível do zoneamento interno do PEl, pois, segundo o Plano de Manejo (2008) são muito bem conservadas. Entretanto, quanto à preservação máxima dos setores naturais, tais áreas não são tão eficientes à proteção integral de ambientes naturais como a Zona Intangível, porque não se localizam dentro dos limites dos Parques ou Estações Ecológicas que são unidades de proteção integral, mas nos limites da APA Serra do Mar, que é uma unidade de uso sustentável, sendo tratadas, conforme a literatura, como entorno de uma unidade de conservação, onde as atividades humanas estão sujeitas a normas e restrições específicas, com o propósito de minimizar os impactos negativos sobre a unidade (Lei n. ${ }^{\circ}$ 9.985/2000 Art. 2o inciso XVIII) (SÃO PAULO, 2008). 
Assim, sua função deveria ser só de preservação integral do ambiente físico, restringindo o uso da terra como uma UC de Proteção Integral, e não fomentar práticas sustentáveis geradoras de renda e minimização de impactos, pois na verdade, suas características físicas não condizem àquelas que uma APA pretende preservar (áreas já alteradas e de uso humano bem consolidado).

Ao observar-se as figuras 4 e 8, percebe-se que a Estação Ecológica Xituê já protege uma amostra desse ambiente potencialmente rico em diversidade beta.
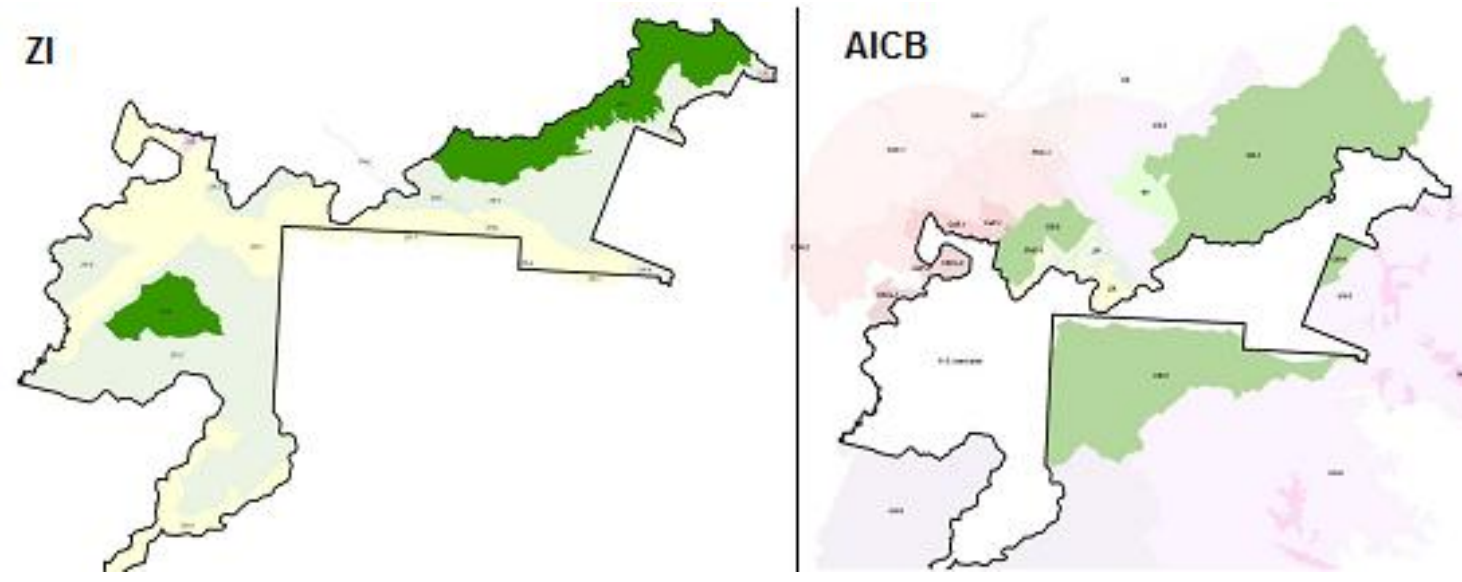

Figura 9: ZI - Zonas Intangíveis do PEI. AICB - Áreas de Interesse à Conservação da Biodiversidade do entorno PEI. Fonte: São Paulo (2008).

Desse modo, para se garantir a proteção do território que engloba essa área com diversidade beta potencilamente mais concentrada, sabendo as características das Unidades de Conservação da Área, propomos que a Área de Interesse à Conservação da Biodiversidade, vizinha a oeste e noroeste da Estação Ecológica de Xituê, seja englobada à mesma, enquanto que a área das demais sejam definidas como territórios de novas estações ecológicas a serem criadas.

Os setores das Áreas de Interesse à Proteção da Biodiversidade que não se dão em terras altas atuariam como área de transição e amortecimento de influencias de ambientes distintos potencialmente menos ricos em diversidade beta ou já consideravelmente perturbados por ações antrópicas por se dar em relevo mais propício ao avanço de perímetros urbanos e rurais.

Dessa forma, a Estação Ecológica teria um significado social importante no mosaico de Unidades de Conservação do Contínuo Ecológico de Paranapiacaba: assim como os Parques estão diretamente associados à proteção de ambientes de serra escarpada em forma de 
paredão, as Estações Ecológicas estariam diretamente associadas à preservação de ambientes de relevo mais suave em excelente estado de conservação físico e biótico, raros e com potencial de diversidade beta maior na área. Além disso, protegeria ambientes que são muito mais suscetíveis à alteração por atividades humanas que os ambientes de escarpa de serra, devido à suavidade maior de seu relevo que não dificulta tanto a expansão do perímetro urbano ou rural dos municípios da área do platô, devendo ser tratadas como zonas de uso restrito da terra, como as Zonas Intangíveis das Unidades de Conservação de Proteção Integrada.

\section{CONCLUSÕES}

Conclui-se que o estudo da fauna pode servir como instrumento para o melhor entendimento da complexidade geográfica de ambientes naturais, quanto à relação de unidades espaciais dadas em escalas distintas.

Dessa forma, podem-se propor melhores formas de apropriação de tais ambientes naturais, principalmente no que se refere ao estabelecimento de unidades de conservação com objetivos de proteção mais eficientes e compatíveis às características dos distintos setores de dada área serrana, mais especificamente a Serra de Paranapiacaba paulista.

Este estudo, apesar de tratar de um tema isolado e muito pouco desenvolvido dentro da ciência geográfica, demonstra que o mesmo pode ser abordado com sucesso. Demais pesquisas devem ser elaboradas para desenvolver melhores métodos utilizados neste tipo de análise, principalmente no desenvolvimento de arcabouço teórico-metodológico sólido que possa ser aplicado a qualquer realidade, sendo testados ou servindo para corroborar, refutar ou desenvolver questões associadas a ideias passíveis de críticas associadas à forma de apropriação da terra.

\section{AGRADECIMENTOS}

À FAPESP - Fundação de Amparo à Pesquisa do Estado de São Paulo - pelo apoio financeiro essencial à realização da pesquisa.

Ao Instituto Florestal - SP, pelo total apoio concedido à realização dos trabalhos de campo.

À Helga Grigorowitschs, pelo auxílio à elaboração das figuras produzidas. 


\section{REFERÊNCIAS BIBLIOGRÁFICAS}

ALEIXO, A. L. P. Estrutura e organização de comunidades de aves em áreas de Mata Atlântica primitiva e explorada por corte seletivo, 1997, 78f. Dissertação (Mestrado em Ciências Biológicas - Ecologia) - Instituto de Biologia, Universidade Estadual de Campinas, Campinas, 1997. Disponível em: http://cutter.unicamp.br/ document/?code=vtls000117575. Acesso em: 12/2009.

ALEIXO, A. L. P.; GALETTI, M. The conservation of the avifauna in a lowland Atlantic forest in south-east Brazil. Bird. Cons. Inter, 7: 235-261, 1997.

ALMEIDA-SCABBIA, Fitossociologia de um trecho de floresta atlântica no Parque Estadual Intervales, SP, 1996, 121f. Dissertação (Mestrado) - Instituto de Biociências, Universidade Estadual Paulista, 1996.

BERTRAND, G. Paisagem e geografia física global: esboço metodológico. Tradução Olga Cruz. Cadernos de Ciências da Terra, IGEO/USP, São Paulo, n. 13, p. 1-27, 1971.

BROWN J. H.; LOMOLINO, M. V. Biogeografia. $2^{\text {a }}$ edição. Ribeirão Preto: FUNPEC, 2006. $691 p$.

CHRISTOFOLETTI, A. As características da nova geografia (1976). In: CHRISTOFOLETTI, A. (org.). Perspectivas da geografia. São Paulo: DIFEL, 1982, p. 71-101.

CORDEIRO, P. A. C. Areografia dos Passeriformes endêmicos da Mata Atlântica. Ararajuba, 9 (2): $2001.25-137, \quad$ Disponível em: http://www.ararajuba.org.br/sbo/ararajuba/artigos/Volume92/ara92art6.pdf. Acesso em: $12 / 2009$.

CORRÊA, R. L. Região: a tradição geográfica. In: Trajetórias Geográficas. 3a edição. São Paulo: Ática, 2005, p. 183-196.

COUTINHO, L. M. Contribuição ao conhecimento da ecologia da mata pluvial tropical: estudo do balanço d'água de sua vegetação, 1960, 184p. Tese (Doutorado) - Instituto de Biociências, Universidade de São Paulo, São Paulo, 1960. 
CUSTÓDIO FILHO, A. A Floresta Ombrófila Densa em diferentes altitudes no Parque

Estadual Carlos Botelho, São Paulo, Brasil. Tese (Doutorado) - Instituto de Biociências, Universidade de São Paulo, São Paulo, 2002.

DAJOZ, R. Princípios de ecologia. $7^{\mathrm{a}}$ edição. Porto Alegre: Artmed, 2006. 519p.

DELPOUX, M. Ecossistema e Paisagem. Tradução: May Christine Moenesi. Métodos em Questão, IGEO/USP, São Paulo, n.13, p. 1-23, 1974.

DEVELEY, P. F. Efeitos da fragmentação e do estado de conservação da floresta na diversidade de aves de Mata Atlântica, 2004, 135p. Tese (Doutorado) - Instituto de Biociências, Universidade de São Paulo, 2004.

FERREIRA, M. C. Mapeamento de unidades de paisagem em sistemas de informação geográfica: alguns pressupostos fundamentais. Geografia, 22 (1): 23- 36, 1997.

FUNDAÇÃO FLORESTAL. Parque Estadual Intervales: Plano de Gestão Ambiental, Fase 1. São Paulo: Fundação Florestal, 1998.

GILLESPIE, T. W. et al. Measuring and modeling biodiversity from space. Progress in Physical Geography, 32 (2): 203-221, 2008.

GREGORY, K. J. A natureza da geografia física. Rio de Janeiro: Bertrand Brasil, 1992.

HOYO, J.; ELLIOTT, A.; CHRISTIE, D (Ed.). Cotingas to pipits and wagtails. In: Handbook of the birds of the world. Volume 9. Barcelona: Lynx Edicions, 2004.

LA BLACHE, P. L. Las divisiones fundamentales del território Frances (1888-1889). In: MENDOZA, J. G.; JIMENÉZ, J. M.; CANTERO, N. O (org.). El pensamiento geográfico. Estudio interpretativo y antologia de textos (De Humboldt a las tendencias radicales). Madrid: Alianza Editorial, 1982, p. 243-249.

MANTOVANI, W.; PAVÃO, T. Vegetação. In: SÃO PAULO (Estado). Secretaria do Meio Ambiente, Fundação Florestal e Departamento de Geografia da Universidade de São Paulo. Plano de Manejo do Parque Estadual Intervales. SÃO PAULO, 2008. Disponível em: http://www.fflorestal.sp.gov.br/planodemanejoCompletos.php. Acesso em: 12/2009 
MARTINS, C. Biogeografia e Ecologia. $5^{\text {a }}$ edição São Paulo: Nobel, 1992. 115p.

METZGeR, J. P. O que é ecologia de paisagens? Biota Neotropica,1, (1/2): 61-69, 2001. Disponível em: www.biotaneotropica.org.br. Acesso em: 12/2009.

OLIVEIRA, R. J. Variação da composição florística e da diversidade alfa das florestas atlânticas no Estado de São Paulo, 2006, 144f. Tese (Doutorado em Biologia Vegetal) Instituto de Biologia, Universidade Estadual de Campinas, Campinas, 2006. Disponível em: http://cutter.unicamp.br/document/?code=vtls000 397353. Acesso em: 12/2009.

OLIVEIRA FILHO, A. T.; FONTES, M. A. L. Patterns of floristic differentiation among Atlantic Forests in Southeastern Brazil, and the influence of Climate. Biotropica, 32: 793-810, 2000.

PIZO, M. A. et al. Frugivory in cotingas of the Atlantic Forest of Southeast Brazil. Ararajuba, 10: $177-185, \quad 2002 . \quad$ Disponível em: http://www.ararajuba.org.br /sbo/ararajuba/artigos/Volume102/ara102art6.pdf. 12/2009.

RAHBEK, C.; GRAVES, G. R. Multiescale assesment of patterns of avian species richness. Proc. Natl. Acad. Sci. USA, 98: 4534-4539, 2001.

SANCHEZ-LACERDA, M. Composição florística e estrutura da comunidade arbórea num gradiente altitudinal da Mata Atlântica, 2001 123p. Tese (Doutorado em Biologia Vegetal) Instituto de Biologia, Universidade Estadual de Campinas, Campinas, 2001. Disponível em: http://cutter.unicamp.br/document/?code=vtls000 215037. Acesso em 12/2009.

SÃO PAULO (Estado). SECRETARIA dO MEIO AMBIENTE; FUNDAÇÃO FLORESTAL \& DEPARTAMENTO DE GEOGRAFIA/USP. Plano de Manejo do Parque Estadual Intervales, 2008. Disponível em: http://www.fflorestal. sp.gov.br/planodemanejoCompletos.php. Acesso em: 12/2009.

SIGRIST, T. Aves do Brasil: uma visão artística = Birds of Brazil: an artistic view. São Paulo: Ministério da Cultura, 2005.672p.

SILVA, A. C. As categorias como fundamentos do conhecimento geográfico. In: REYNAUD, A. et al. O espaço interdisciplinar. São Paulo: Nobel, 1986, p. 25-37. 
SIMONETTI, C. As relações entre o relevo, os solos e a floresta Atlântica na Serra do Mar (bacia do rio Itamambuca, Ubatuba, SP), 2001, 160. Tese (Doutorado) - Instituto de Biociências, Universidade de São Paulo, São Paulo, 2001.

STEVENS, G. C. The latitudinal gradient in gradient range: how so many species coexist in the tropics? The American Naturalist, v. 133, n.2, p. 240 - 256, 1989.

SNOW, D. The Cotingas: bellbirds, umbrellabirds, and other species. London; Ithaca, N.Y.: British Museum (Natural History): Comstock Pub. Associates, 1982. 203p.

TARIFA, J. R. Os climas nos maciços litorâneos da Juréia-Itatins: um ensaio de ritmanálise, 2002, 2 v. Tese (Livre Docência) - Faculdade de Filosofia Letras e Ciências Humanas, Universidade de São Paulo, São Paulo, 2002.

TURNER, M. G. Landscape ecology: the effect of pattern on process. In: Annu. Rev. Ecol. Syst., 20: 171-197, 1989. Disponível em: http://www2.fiu.edu/ seagrass/ class/pcb5443/Turner_1989(4).pdf. Acesso em: 04/2010.

VELOSO, H. P.; GÓES FILHO, L. Fitogeografia brasileira: classificação fisionômico-ecológica da vegetação neotropical. Salvador: Ministério das Minas e Energia, 1982. 85p.

VELOSO, H. P.; KLEIN, R. M. As comunidades e associações vegetais da mata pluvial do sul do Brasil. I. As comunidades do município de Brusque, Estado de Santa Catarina. Sellowia, Itajaí, 9 (8): 81-235, 1957.

ZUNINO, M. A.; ZULINI, A. Biogeografía: la dimensión espacial de la evolución. México: Fondo de Cultura Económica, 2003. 359p.

Artigo recebido em 08/03/2012.

Artigo aceito em 12/04/2012. 